\title{
Diez tesis sobre el conflicto social en América Latina
}

\author{
Fernando Calderón $G$.
}

RESUMEN

La conflictividad en los países de América Latina presenta rasgos comunes:

plataformas de exclusión y desigualdades crónicas cuestionadas por la ciudadanía; conflictos complejos que relacionan esas desigualdades con su número e intensidad; combinación de protestas sociales expresadas tanto en el plano nacional como en el cultural global; racionalidades prácticas en las tensiones originadas por la reproducción social ${ }^{1}$ que conviven con demandas de mayor eficacia y eficiencia institucional y con conflictos culturales sistémicos. Asimismo, Estados omnipresentes en todas las esferas conflictivas, con limitaciones para procesarlas, y sociedades con conflictos fragmentados; nuevos espacios públicos donde las tensiones se representan de manera contradictoria y conflictos que se desplazan a las redes de información y comunicación con efectos multiplicadores en los nuevos escenarios de poder. Existe una mayor complejidad social relacionada con sistemas políticos y Estados con limitadas capacidades de gestión. Las situaciones y los escenarios prospectivos son diversos y sus opciones abiertas.

PALABRAS CLAVE

CLASIFICACIÓN JEL

AUTOR
Conflicto social, aspectos sociales, aspectos culturales, condiciones sociales, distribución del ingreso, integración social, igualdad, descentralización gubernamental, medios de comunicación de masas, América Latina

$\mathrm{O} 15, \mathrm{O} 54, \mathrm{Y} 90$

Fernando Calderón G. es asesor regional del Proyecto de Análisis Político y Escenarios Prospectivos (PAPEP) y profesor e investigador en la Facultad Latinoamericana de Ciencias Sociales (fLAcso), sede Argentina. naniascalderon@gmail.com

${ }^{1}$ Se refiere a que en los actores predomina una lógica de resultados concretos en favor de sus necesidades de reproducción social. Los relatos ideológicos son circunstanciales a los momentos políticos vividos. 


\section{I}

\section{El contexto}

El mundo de hoy vive un momento crucial, porque en él se condensan al mismo tiempo varias y diferentes crisis, así como transformaciones y opciones de tipo financiero, multicultural, de carácter ecológico y político. Lo inédito es que se asiste y se está en medio de una manifestación de cambios con características múltiples.

Algunos rasgos de la globalización están experimentando una transformación trascendental y hay una recomposición profunda del poder económico y de las fuentes para el crecimiento económico del planeta. Un nuevo multilateralismo se está instalando. Las nuevas economías emergentes asumen modelos "heterodoxos" de capitalismo o de economía de mercado, vinculados a orientaciones políticas con discursos ideológicos divergentes: reformismo práctico, nacional/popular ${ }^{2}$, "neodesarrollismo indigenista" y modernización conservadora (Calderón, 2008).

En América Latina la economía creció, se logró disminuir la pobreza y se avanzó en algunos efectos distributivos (CEPAL, 2010a; PNUD, 2009). La región ha mostrado singulares capacidades políticas y de gestión para enfrentar la crisis global. Además, sus proyecciones de crecimiento son relativamente favorables (Aranibar, Vázquez y Garzón, 2011).

Sin embargo, la transformación productiva y el salto hacia una economía del conocimiento no parecerían estarse dando con el dinamismo requerido para avanzar en la solución de los graves problemas de pobreza y desigualdad en la región. La innovación e inclusión social son todavía una ecuación pendiente. En igual sentido, han mejorado varios indicadores de legitimidad política; sin embargo, los avances hacia una democracia de ciudadanos son insuficientes (PNUD, 2004).

El problema es: ¿Cómo avanzar en ese sentido? ¿Qué capacidades políticas supone? ¿Cómo combinar hábilmente crecimiento, redistribución y sostenibilidad ambiental? ¿Cómo asociar el ciclo político que vive la

$\square$ Se agradece la colaboración de Lorenza Fontana, María Isabel Nava y Huascar Pacheco en la elaboración de este documento, al PAPEP-Programa de las Naciones Unidas para el Desarrollo (PNUD), y asimismo a la Fundación UNIR Bolivia por facilitar el uso de los resultados del informe Los conflictos sociales en América Latina, que fue coordinado por el autor.

${ }^{2}$ El pueblo se identifica con la Nación y el Estado. Véase Calderón (2008). región con un ciclo de transformaciones en las matrices económico-productivas? ¿Cómo persistir en la construcción de institucionalidad y pluralismo cultural de manera adecuada a un cambio económico innovador? Precisamente, un tema central en todos estos procesos es el del conflicto social y de sus formas de abordarlo en una perspectiva en que la democracia se entiende como un orden conflictivo. Justamente en este ámbito es donde se sitúa el presente trabajo. Las tesis que se presentan a continuación requieren ser miradas desde una triple perspectiva: histórica, conceptual y como parte del proceso de cambios a escala global.

En la mayoría de los países de la región, el rasgo histórico, central y común en la dinámica contemporánea de los conflictos se refiere a la aparición temprana del Estado como actor social, que no solo refleja la conflictividad social y política de las sociedades, sino que también actúa en la conformación de los sistemas de intereses económicos y de actores políticos que definen la dinámica del conflicto.

La formación de un Estado Nación autónomo, la industrialización y el desarrollo de un proceso de modernización inclusivo, alimentado por una sólida cultura nacional/popular ${ }^{3}$, fueron las metas y los ejes de organización de los conflictos en el ciclo del primer populismo que experimentó la región (Touraine, 1988).

Bajo las dictaduras, los conflictos que produjeron los actores sociales se centraban en una acción puramente defensiva, ya que los autoritarismos "resolvían" con represión cualquier expresión de naturaleza conflictiva. En ese marco se desarrollaron con creciente intensidad luchas y demandas por los derechos humanos y la democratización política (Ansaldi, 1986).

La democratización dio paso a nuevos campos de conflictividad, y a la revitalización, emergencia o ambas de nuevos movimientos sociales. Esta temática se encuentra analizada en la serie de estudios nacionales Los movimientos sociales ante la crisis (Calderón, 1986). En ese estudio, un primer campo de conflicto se refirió a la defensa de la condición obrera. Un segundo campo

\footnotetext{
${ }^{3}$ Una cultura nacional popular es aquella en que se procura la hegemonía política, la centralización del Estado en la organización del desarrollo y la democracia, la movilización de masas y un liderazgo carismático.
} 
aludió a las demandas de calidad de la vida urbana, el consumo colectivo y la descentralización. Un tercer campo vinculó a los conflictos campesinos en relación con la tierra, el mercado y el reconocimiento étnico. Los derechos humanos y la búsqueda de relaciones de género equitativas fueron otro campo significativo en dicho período.

Luego de las reformas estructurales, el conflicto fue en defensa de las condiciones de vida y a causa del malestar introducido por la cosificación del mercado. A fines de los años noventa, como parte de una inflexión histórica tanto en términos de democracia como de desarrollo, emergió un nuevo tipo de conflicto con una mayor complejidad social y rasgos multifacéticos, multiplicándose tanto los conflictos como los actores. En este contexto, sobresalen los conflictos vinculados al multiculturalismo y los planteamientos relacionados con nuevas formas de calidad de vida, la ciudadanía y la dignidad (PAPEP-PNUD, 2011).

Conceptualmente se puede afirmar que en los conflictos en la región se enlazan demandas de libertad real y libertad cultural. La primera, entendida como un conjunto de demandas destinadas a satisfacer necesidades de una vida digna y desde allí poder desarrollar capacidades y optar por el tipo de vida que se desea llevar, de acuerdo con valores y aspiraciones propias. La segunda, entendida como el reconocimiento de las identidades y los derechos de las personas y las comunidades culturales, en relación con el derecho de asumir y de cambiar identidades (Sen, 1999; PNUD, 2004).

En el enfoque conceptual del artículo se considera a la política constructivista como la mejor forma de procesar los conflictos ${ }^{4}$. El constructivismo político asume las realidades socioeconómicas y los juegos de poder procurando fortalecer la democracia y parte del reconocimiento de una pluralidad sociocultural para construir un orden común, sin desconocer que tal orden es el resultado de un proceso conflictivo. El conflicto no es sinónimo de guerra; es más bien el orden conflictivo de la diversidad y la interculturalidad el que supone la

\footnotetext{
${ }^{4}$ El constructivismo político se asienta en la capacidad política de los actores para producir un orden conflictivo resultado de la interacción y el reconocimiento entre diferentes u opuestos, lo que supone comprender la libertad y la identidad del otro. La política constructiva podrá ser entendida como el arte de lo mejor posible. La modalidad de hacer política es la de un intercambio de reconocimientos recíprocos (PAPEP-PNUD, 2011, cap. 1). Metodológicamente, para explicar este tipo de acción resulta fundamental determinar los datos estructurales e institucionales sobre los que descansa la acción, como también los efectos de la socialización a la que están vinculados los actores (Boudon y Bourricaud, 1982, pág. 308).
}

democracia y la paz. En este enfoque, la política y los actores sociales se hacen y rehacen constantemente en el conflicto y este se alimenta de relaciones desiguales de poder que también son reales e históricas. Por esto, los actores se forman en la política donde todos están sometidos a relaciones de poder. En el texto se sintetiza una visión normativa de la política, como una política orientada por valores. Como decía Gianni Vattimo, no es cuando tenemos la verdad que nos ponemos de acuerdo; es más bien cuando nos ponemos de acuerdo que encontramos la verdad (Vattimo, 2006).

Aquí no se argumenta en favor o en contra de un tipo de sociedad determinada; se argumenta, sobre todo, por una forma política institucional de convivir entre diferentes, que permita construir metas compartidas sin negar el poder, ni el conflicto o la discrepancia en numerosos planos. La política, en este sentido, no sería un instrumento de negociación, sino un ejercicio de comprensión de la memoria y de la libertad del otro.

En esta perspectiva se plantea que una sociedad que produce conflictos y cambios que son procesados constructiva e institucionalmente, será más fecunda en democracia y desarrollo, mientras que si la sociedad produce conflictos y sus instituciones son débiles en el procesamiento de estos, los resultados en términos de democracia y desarrollo serán problemáticos, como también si la sociedad muestra debilidad en producir conflictos y cambios y sus instituciones son fuertes, pero no saben procesar los conflictos democráticamente. En situaciones donde la sociedad, el Estado y sus instituciones son débiles, como se verá más adelante, predominarían sistemas informales de intermediación y control en la reproducción del orden social. Para América Latina las ideas clásicas de Marcel Mauss son aún importantes.

En definitiva, ¿cómo afectan los conflictos a las opciones de democracia y desarrollo? Responder a esta inquietud es precisamente el propósito del presente artículo.

Metodológicamente, los conflictos encontrados e interpretados en el estudio han sido el resultado de las narraciones elaboradas durante un año por 54 periódicos en 17 países de la región. Estos medios representan diversas orientaciones ideológicas, tienen importantes mercados de información y son en buena medida componentes de complejas redes a escala global y local, que funcionan a partir del uso y desarrollo de las nuevas tecnologías de la información y las comunicaciones (TIC). En este sentido, es muy importante subrayar que la base empírica de este trabajo son los conflictos sobre los que publicaron los periódicos seleccionados. Si bien estos contribuyeron, junto con otros medios, a formar la opinión pública 
respecto de aquellos hechos, no abordaron los conflictos existentes que son más numerosos que los publicados. Desde luego, esto representa una seria limitación para este tipo de estudios, donde además es frecuente confundir lo publicado con la realidad. Sin embargo, se realizaron pruebas de consistencia por medio de otras fuentes estadísticas sobre casos nacionales y sectoriales y se encontraron tendencias cualitativas similares. No obstante, debe quedar claro que la información es insuficiente. Aquí principalmente se estudiaron los conflictos en el espacio público comunicacional basado en la prensa escrita.

En términos cuantitativos, América Latina se confirma como una región con una conflictividad significativa. Empero, el tiempo de estudio correspondió a un período de "salida" de la crisis global y de relativa estabilidad sociopolítica. Se trata de un lapso en que el casillero en que aparecen una alta radicalidad y un gran número de conflictos está vacío. No hubo crisis serias de gobernabilidad en la región, a excepción del golpe de Estado en Honduras. En el análisis se detectaron - entre octubre de 2009 y septiembre de 2010 - 2.318 conflictos y 4.724 episodios conflictivos. En términos generales, los países que registran el mayor número de conflictos son la Argentina, Bolivia (Estado Plurinacional de) y el Perú, con un total de conflictos superior a los 200. Los países con menos conflictos de la región son Chile, Costa Rica y El Salvador, con un promedio de 58 conflictos. Los países con mayor radicalidad de los conflictos son Chile, la República Dominicana y Venezuela (República Bolivariana de), y con menor radicalidad: Costa Rica, Panamá y el Perú. En el gráfico 1 sobre la radicalización de los conflictos se registra su intensidad. Y con esto se abre la caja de Pandora.

\section{Pirámide de radicalización}

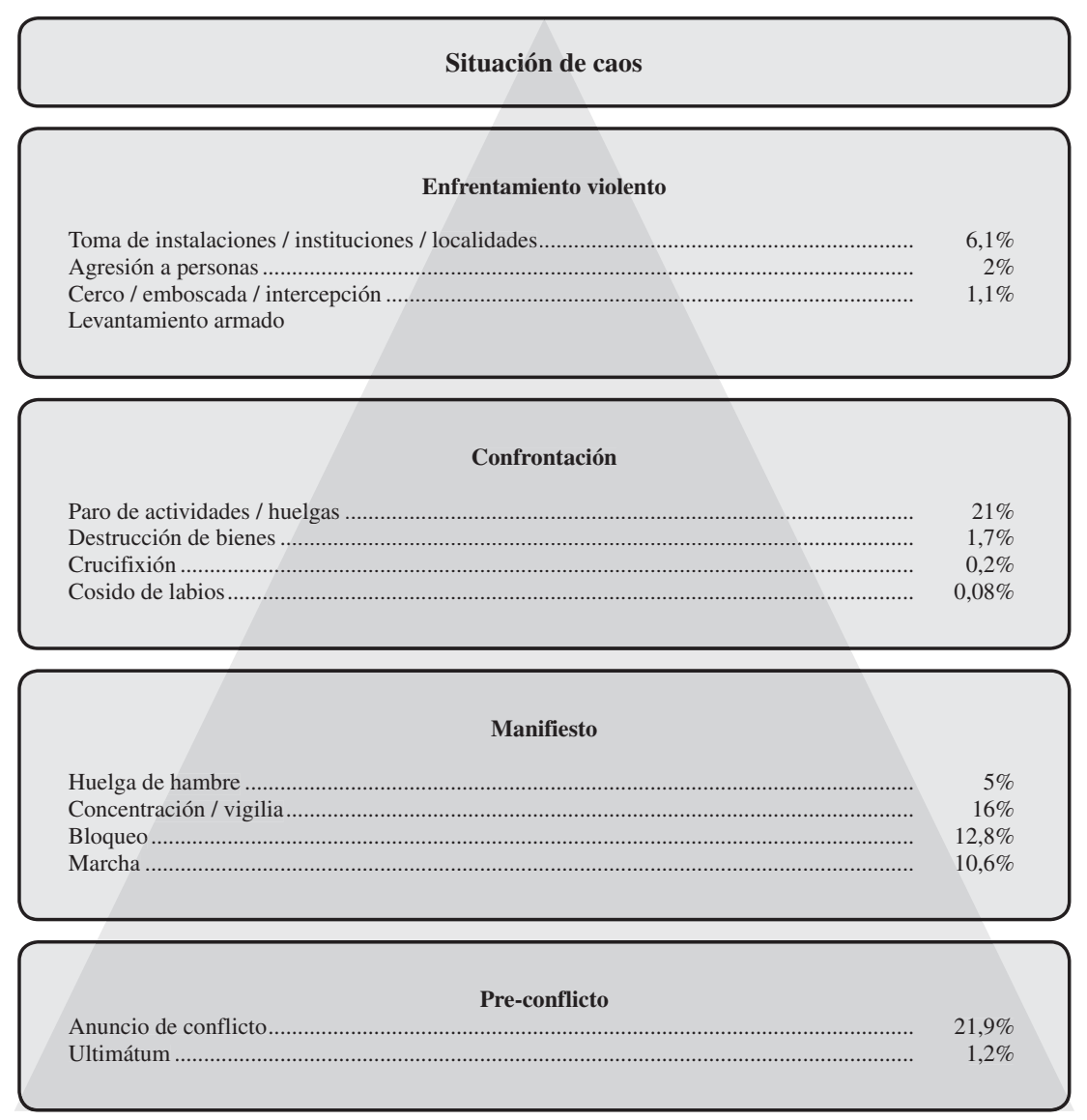

Fuente: Proyecto Análisis Político y Escenarios Prospectivos-Programa de las Naciones Unidas para el Desarrollo (PAPEP-PNUD), Los conflictos sociales en América Latina, La Paz, 2011. 


\section{II}

\section{Las tesis}

En las tesis que se presentan a continuación se acentúan las características más frecuentes, los rasgos comunes y los desafíos compartidos que enfrentan las diferentes sociedades latinoamericanas.

\section{Tesis 1}

Los rasgos que asume la compleja desigualdad en América Latina se vinculan no solo a significativos niveles de diferenciación social y altos niveles de concentración de ingresos y riqueza, sino también al malestar y el cuestionamiento por parte de los ciudadanos a tales niveles de desigualdad. Este es el motivo por el cual la desigualdad constituye la base sobre la que se desarrollan la mayoría de los conflictos y protestas sociales en la región.

América Latina ha disfrutado de un entorno económico favorable, que se ha visto reforzado por una macroeconomía sana, alto crecimiento y cierto grado de redistribución por la vía de políticas sociales; sin embargo, en la región se mantiene la desigualdad como un problema estructural. En el Informe regional sobre desarrollo humano para América Latina y el Caribe del PNUD 2010 se mencionan tres rasgos característicos de la desigualdad en América Latina y el Caribe: es alta, persistente y se reproduce en un contexto de baja movilidad socioeconómica. Asimismo, se destaca que los países de la región se encuentran entre los más desiguales del mundo en ingreso per cápita de los hogares: 10 de los 15 países más desiguales del mundo son latinoamericanos. Así, el coeficiente de Gini del ingreso de América Latina y el Caribe es " $65 \%$ más alto que en los países de ingresos altos, $36 \%$ más elevado que en los países de Asia oriental y $18 \%$ superior al del África" (PNUD, 2010).

En el gráfico 2 se muestran los altos niveles de concentración en la distribución del ingreso en la región, donde el $20 \%$ más rico de la población posee el $56,81 \%$ de los ingresos y el $20 \%$ más pobre solamente el 3,4\%. Según la revista Forbes, los más ricos de América Latina acumulan 332 mil millones de dólares, 17 veces más que el producto interno bruto (PIB) de Bolivia (Estado Plurinacional de) y 19 veces más que el PIB del Paraguay (Forbes, 2011).

Los ciudadanos perciben como injustos estos niveles de desigualdad y hay una demanda instalada de cambio que explica la fuerza de los conflictos sociales, incluso
GRÁFICO 2

Distribución del ingreso: Copa de champagne (En porcentaje)

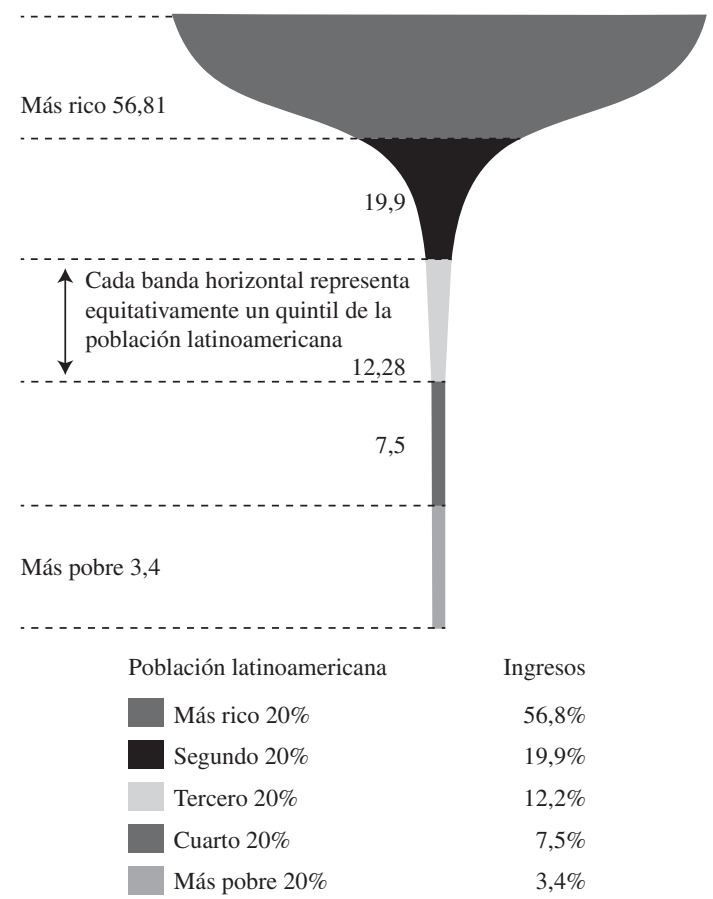

Fuente: elaboración propia sobre la base de datos de la Comisión Económica para América Latina y el Caribe (CEPAL), "CEPALSTAT. Estadísticas de América Latina y el Caribe”, 2009.

en situaciones de importantes avances en la disminución de la pobreza que ha tenido América Latina ${ }^{5}$ (véase el gráfico 3). Según datos del Informe Latinobarómetro 2010, el 79\% de los latinoamericanos consideran injusta la distribución del ingreso.

\section{Tesis 2}

El espacio público mediático es el lugar donde se expresan crecientemente los conflictos sociales y donde se construyen los relatos sobre estos. Está relacionado con la expansión y multiplicación masiva de las nuevas

\footnotetext{
5 Según el Panorama social de América Latina, en 2010 la cantidad de personas pobres disminuyó un 5\% retomando la tendencia regional a la reducción de la pobreza, que comenzó en 2003 (CEPAL, 2010c).
} 
Cuán justa es la distribución de la riqueza en América Latina 2010

(Percepción de la distribución de la riqueza)

Pregunta: ¿Cuán justa cree Ud. que es la distribución del ingreso en (país)?

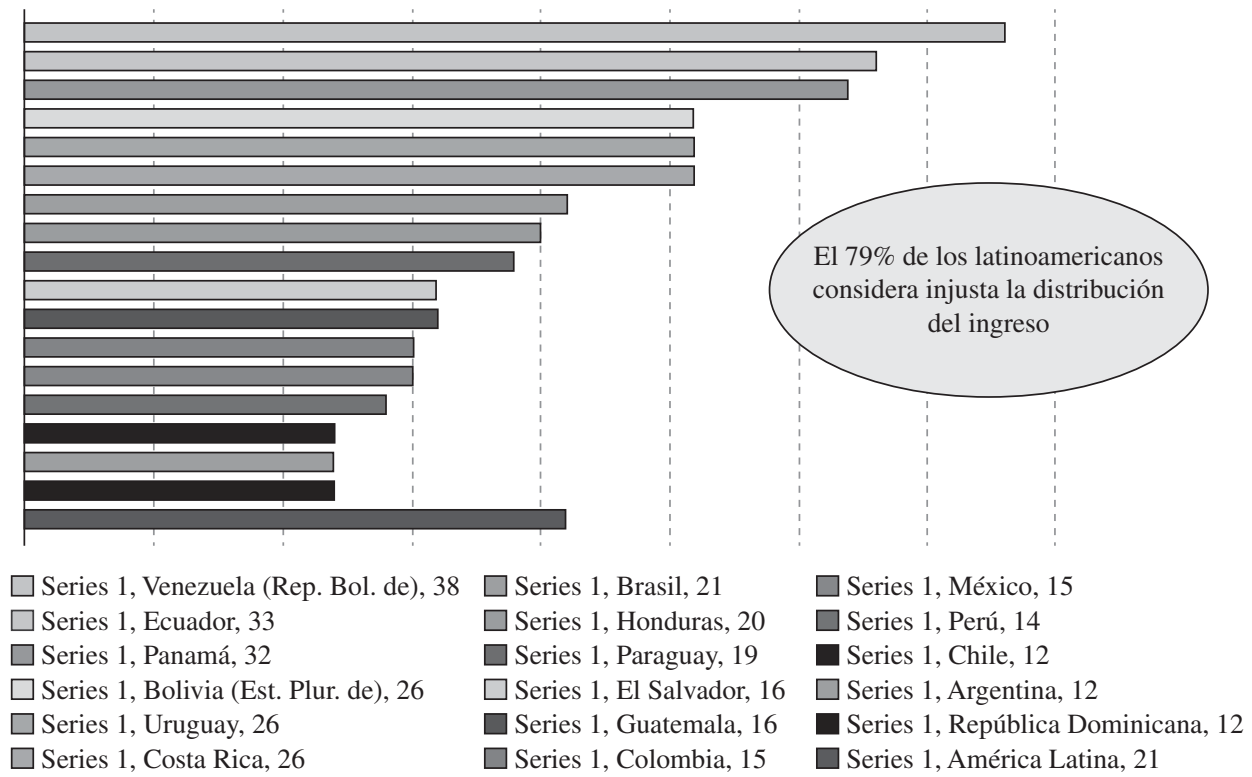

Fuente: Corporación Latinobarómetro, Informe Latinobarómetro 2010, Santiago de Chile, 2010 (en línea) http:// www.latinobarometro.org/ latino/LATDatos.jsp

TIC. Los actores en conflicto necesitan a los medios y los medios necesitan los conflictos en una lógica mediática del conflicto y del poder.

Los medios constituyen fuentes de poder, son instituciones y empresas que construyen significados e imaginarios públicos sobre el conflicto, socializando a las personas. Así como los medios necesitan de los conflictos, los conflictos necesitan de los medios, que son espacios públicos en que se reflejan, crean y disputan las relaciones de poder, y donde se reconocen los conflictos entre los actores en pugna. Los medios no son neutrales, pero tampoco instrumentos mecánicos de poder; constituyen el lugar donde se expresan los intereses políticos y sociales, y donde confluyen las distintas miradas periodísticas. Y son también negocios. Sus características dependerán del mercado y del juego de intereses y presiones de los actores.

La concentración de la propiedad de los medios de comunicación se ve reflejada en los tipos de conglomerados mediáticos latinoamericanos. Se ha detectado que en la región conviven tres tipos o tamaños de conglomerados mediáticos. El primero, que podría denominarse "grande", posee propiedades en diversa medida en las cuatro plataformas comunicacionales clave del mercado global (prensa escrita, medios audiovisuales, plataformas web y multimedia móvil) a nivel regional; también debe considerarse aquel que, a pesar de no participar en los cuatro segmentos, concentra en alguno de ellos una gran cantidad de medios considerados relevantes en niveles locales. El segundo grupo, o categoría denominada "mediana", se refiere a aquellas corporaciones que no poseen medios fuera del ámbito nacional, pero que operan en tres o cuatro de los niveles comunicacionales de su ámbito local. Finalmente, existe un grupo o conglomerado "pequeño", en su mayoría de empresas editoriales que poseen cada vez mayores capacidades de ofrecer productos en distintas plataformas orientadas a diversas audiencias, que no poseen más de un par de medios de prensa escrita, no ostentan plataformas complejas de distribución, ni participan de grandes redes de información y comunicación a escala regional o global. En el cuadro 1 se ejemplifican los rasgos de los grupos mencionados. 
CUADRO 1

Tipos de conglomerados mediáticos

Grupo mediático "Grande”

\begin{tabular}{ll}
\hline Periódico & Grupo multimedia \\
\hline El País (Uruguay) & Grupo de Diarios de América \\
O Globo (Brasil) & Organizaçães Globo / GDA Grupo de Diarios de América \\
El Mercurio (Chile) & GDA Grupo de Diarios de América \\
La Tercera (Chile) & Grupo Copesa S.A. / Consorcio Periodístico de Chile \\
Reforma (México) & Grupo Reforma \\
La Prensa (Argentina) & Multimedios la Capital \\
\hline
\end{tabular}

Grupo mediático "Mediano"

\begin{tabular}{ll}
\hline Periódico Grupo multimedia & Grima
\end{tabular}

El Tiempo (Colombia)

El Comercio (Perú)

El Periódico (Guatemala)

El Universal (México)

El Panamá América (Panamá)

El Nacional (República Dominicana)

El Colombiano (Colombia)

Ultimas Noticias (Venezuela)

La Nación (Costa Rica)

La Prensa Gráfica (El Salvador)

Diario Libre (República Dominicana)

Periódicos asociados latinoamericanos

La Nación (Paraguay)

La República (Uruguay)

El Espectador (Colombia)

La Prensa (Honduras)

La Jornada (México)

El Día (República Dominicana)

Jornal de Brasilia (Brasil)

O Estado de São Paulo (Brasil)

El Deber (Bolivia)

Los Tiempos (Bolivia)

La Razón (Bolivia)

El Heraldo (Honduras)

La Nación (Argentina)

\section{Grupo Planeta}

GDA Grupo de Diarios de América

Media Development Loan Fund (MDLF)

GDA Grupo de Diarios de América

Grupo Epasa

Grupo Corripio

Periódicos Asociados Latinoamericanos

Cadena Capriles

GDA Grupo de Diarios de América

Grupo Dutriz

OMNIMEDIA Grupo Multimedia

Grupo Nación de Comunicaciones

Grupo ICK

Grupo Bavaria

Grupo opsa (Organización Publicitaria Sociedad Anónima)

Grupo Corripio

Grupo Jornal de Brasilia

Grupo Estado

Grupo Líder

Grupo Líder

Grupo Líder

Grupo opsa (Organización Publicitaria Sociedad Anónima)

La Nación S.A.

Grupo mediático "Pequeño"

Periódico

$A B C$ Color (Paraguay)

El Universo (Ecuador)

El Universal (Venezuela)

El Diario de Hoy (El Salvador)

La Tribuna (Honduras)

El Mercurio (Ecuador)

Expreso (Perú) Diario

Prensa Libre (Guatemala)

La Nación (Chile)

Correo (Perú)

Crónica (Paraguay)

Expreso (Ecuador)

La República (Costa Rica)

El Mundo (El Salvador)

La Hora (Guatemala)

La Prensa (Panamá)

Página 12 (Argentina)

Jornal do Brasil (Brasil)
Grupo multimedia

Editorial Azeta S.A.

Grupo El Universo

Periódicos Asociados Latinoamericanos

América Interactiva

Carlos Roberto Flores Facussé

Grupo Merchán

Expreso S.A.

Casa Editorial Prensa Libre S.A.

Empresa Periodística La Nación S.A. / Estado chileno

Empresa Periodística Nacional S.A. (EPENSA)

Grupo Nacional de Comunicaciones

Grupo Granasa (Gráficos Nacionales S.A.)

República Media Group (RMG)

Grupo Mundo Multimedia

Familia Marroquín

Corporación La Prensa S.A. (Corprensa)

Editorial La Página S.A.

Nelson Tanure / Editora Jornal do Brasil

Fuente: Proyecto Análisis Político y Escenarios Prospectivos-Programa de las Naciones Unidas para el Desarrollo (PAPEP-PNUD), Los conflictos sociales en América Latina, La Paz, 2011. 
En la dialéctica medios/sociedad no solo hay una relación complementaria entre los medios y los actores en conflicto. Desde una perspectiva constructivista, los medios construyen realidad, contribuyendo a dibujar narrativas e imaginarios que acaban repercutiendo en el mundo real, es decir, en el sistema político, en el proceso de toma de decisiones y en las agencias de los actores sociales.

\section{Tesis 3}

Los conflictos tienen racionalidades complejas e intensidades distintas. Su frecuencia es diferente a su radicalidad y ambas están desigualmente relacionadas con los niveles de institucionalidad y las brechas sociales. Así, a mayores brechas sociales y menores niveles de legitimidad institucional, mayor cantidad de conflictos.
Asimismo, cuanto mayor sea el apoyo al régimen político institucional, menor será la cantidad de conflictos que lleguen a niveles de enfrentamientos violentos.

Uno de los patrones de la conflictividad social en la región encontrados en el presente estudio es la asincronía del conflicto, es decir, conflictos con distinta dirección, intensidad y sentido, vinculados a la búsqueda de niveles de vida básicos, con demandas (sobre todo al Estado) de gestión institucional eficaz y legítima y con estrategias de cambios en las dinámicas de convivencia intercultural. Al mismo tiempo, uno de los hallazgos centrales del estudio se refiere a la complejidad de la asincronía del conflicto, puesto que — como ya se dijobrechas sociales más profundas y menor legitimidad del régimen institucional se traducirán en un mayor número de conflictos (véase el gráfico 4)

GRÁFICO 4

Relación entre apoyo al régimen institucional y número de conflictos/promedio de radicalización, 2010a

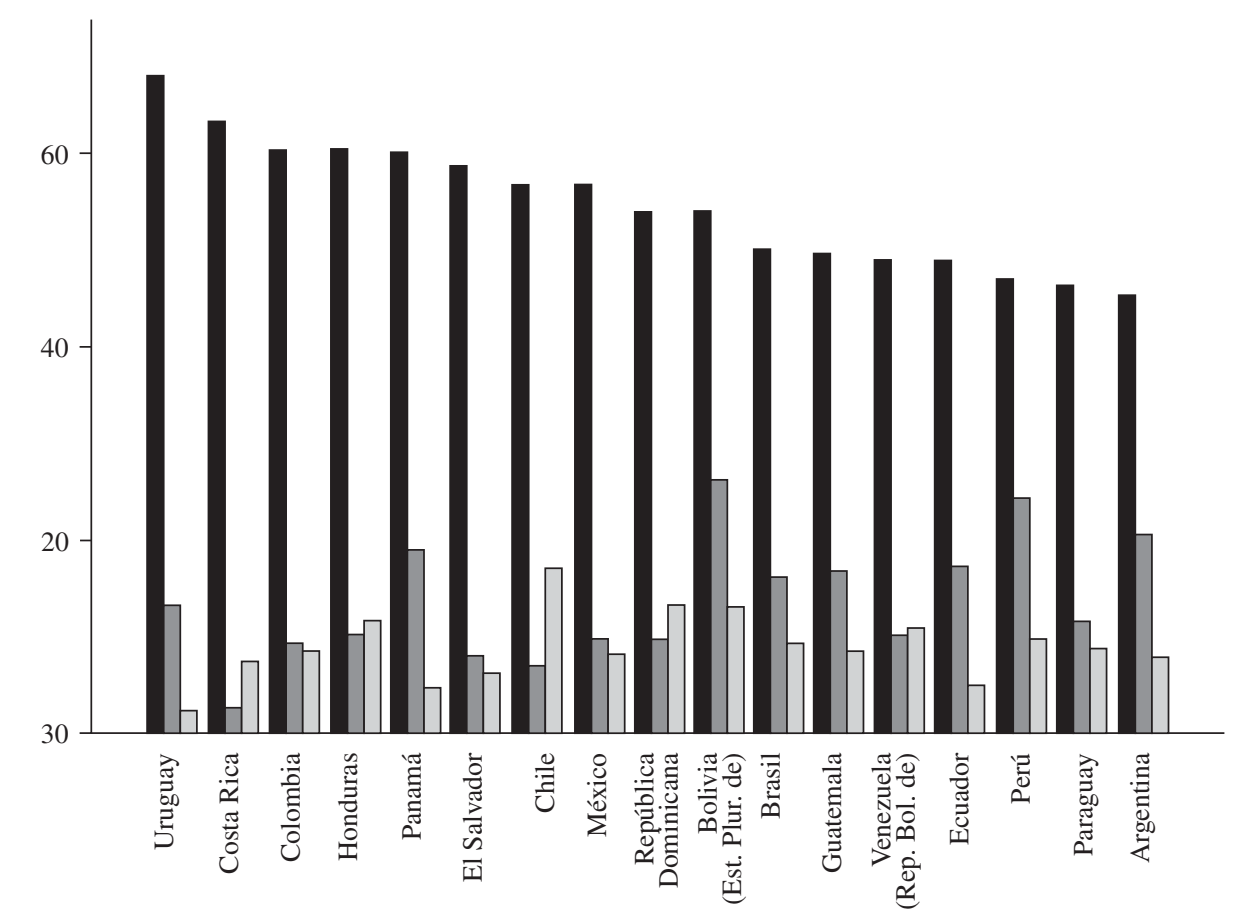

Promedio de legitimidad (LAPOP 2010) $\square$ Número de conflictos (10) $\square$ Porcentajes de conflictos violentos

Fuente: Proyecto Análisis Político y Escenarios Prospectivos-Programa de las Naciones Unidas para el Desarrollo (PAPEP-PNUD), Los conflictos sociales en América Latina, La Paz, 2011.

a No existe una correlación significativa ni relevante entre niveles de legitimidad institucional y radicalización de los conflictos; la lectura del gráfico permite afirmar que no existe una relación evidente entre legitimidad e intensidad del conflicto en la región. Parece existir, por otra parte, una relación entre la cantidad de conflictos y el nivel de legitimidad institucional: países con niveles de legitimidad institucional más bajos parecerían ser más propensos al conflicto social, pese a que esta relación no sea concluyente y solo marginalmente significativa en términos estadísticos. 
Por otra parte, la relación entre radicalidad de los conflictos, legitimidad institucional, brechas sociales y número de conflictos es muy importante, pero más compleja. Como se señaló anteriormente, del nivel de apoyo al régimen institucional dependerá si los conflictos llegan o no a desembocar en enfrentamientos violentos (véase el gráfico 5).

La relación que tienen las brechas sociales con la radicalización no es lineal, sino que dibuja una "U" en la que los países con brechas medias presentan menos casos de violencia y enfrentamientos que los países con brechas amplias y los países con brechas bajas. Esto obedecería a las diferentes formas de interacción entre sociedad, Estado y conflictos, a la capacidad de procesamiento de estos y, en general, a la cultura política y la trayectoria histórica de los países. A todo esto, una buena noticia se ha instalado en la región, pues existe un "casillero vacío" que favorece a la democracia y al desarrollo: la conflictividad social en los países latinoamericanos no es muy alta ni muy radicalizada.

\section{Tesis 4}

El Estado es un actor central en los juegos de poder y de conflicto, pero tiene limitada capacidad de gestionarlos y resolverlos con un sentido de cohesión social y expansión democrática. Este factor conduce a una paradoja, ya que los Estados catalizan las demandas sociales, pero no tienen la capacidad suficiente para gestionarlas.

Como se demuestra en el gráfico 6, por una parte, en América Latina el principal actor demandado es el Estado en el $70 \%$ de los casos, es decir, la instancia hacia la que se dirige el malestar social en la búsqueda de la satisfacción de una demanda o la consecución de un objetivo. Por otra parte, la sociedad está experimentando un proceso de progresiva fragmentación de los actores colectivos y de sus identidades, lo que se refleja en una tendencia a la multiplicación de las demandas fuera de los marcos clásicos e institucionalizados de los conflictos.

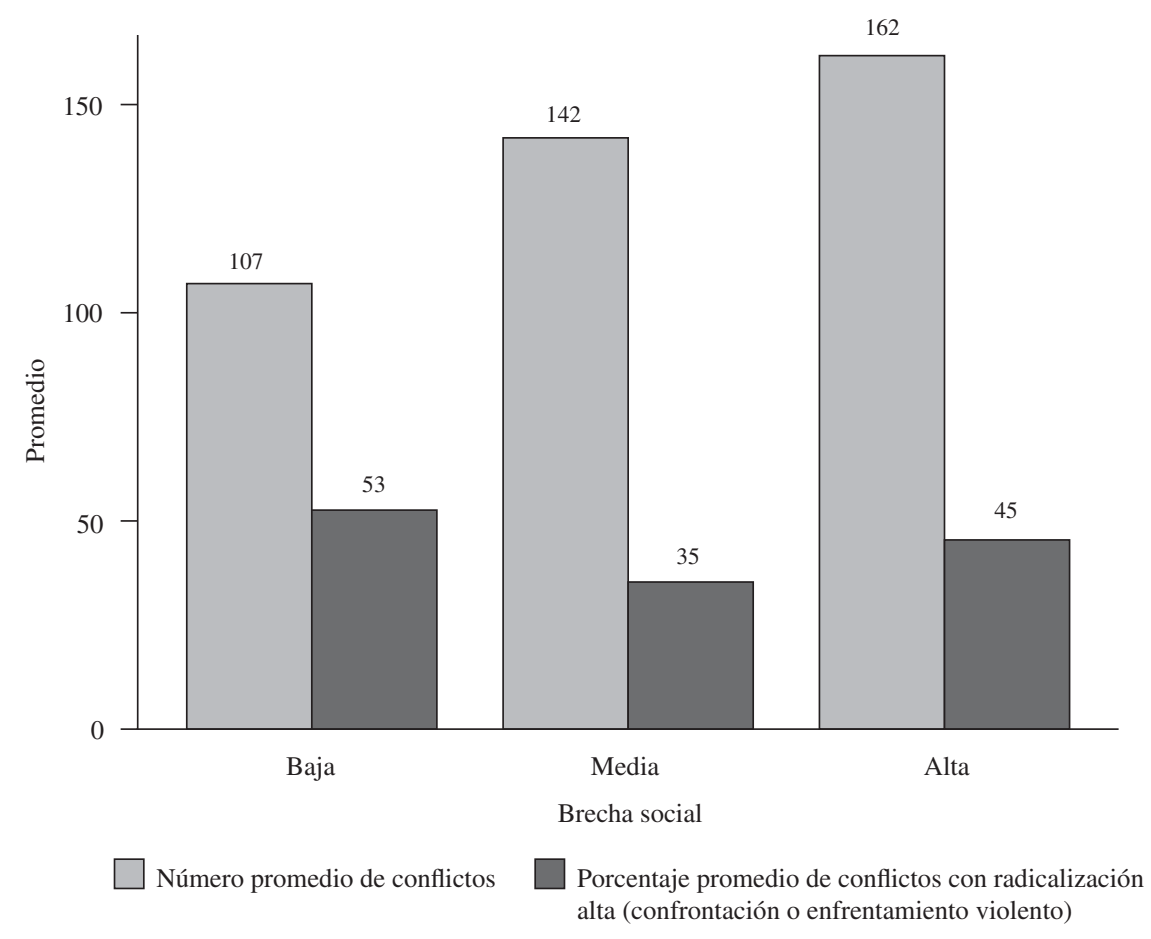

Fuente: Proyecto Análisis Político y Escenarios Prospectivos-Programa de las Naciones Unidas para el Desarrollo (PAPEP-PNUD), Los conflictos sociales en América Latina, La Paz, 2011. 
Actores demandados y demandantes ${ }^{a}$
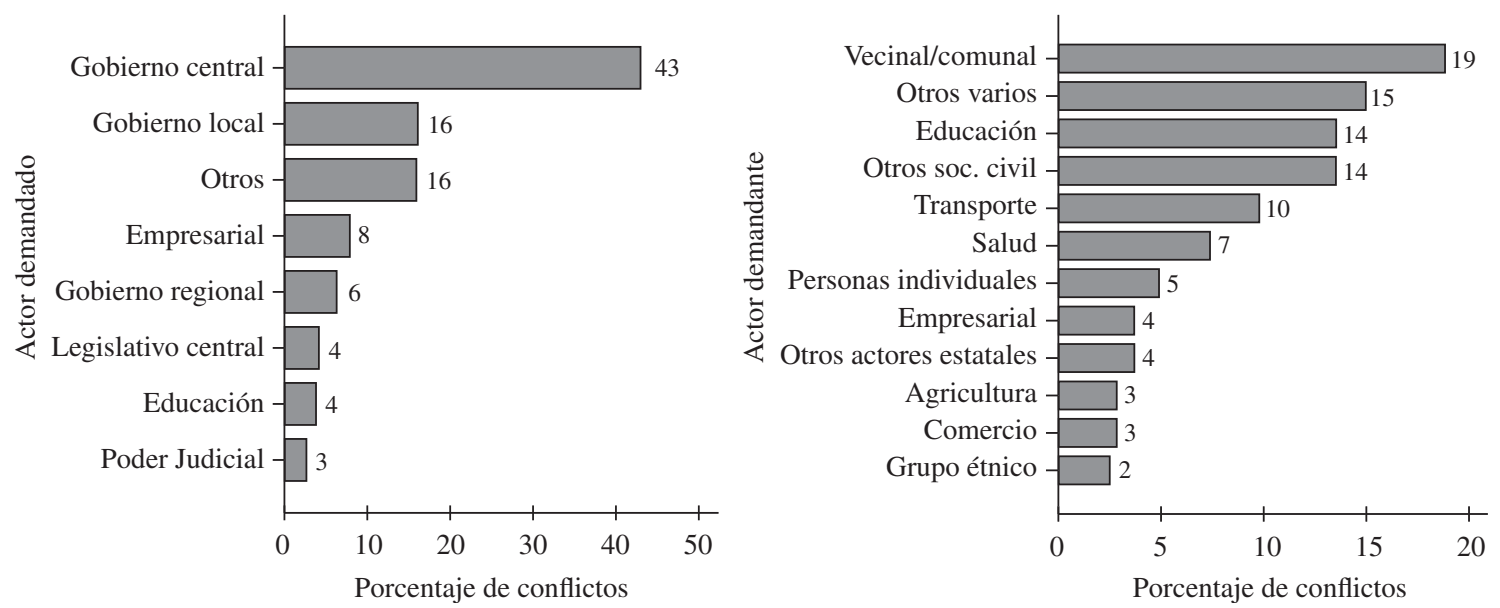

Fuente: Proyecto Análisis Político y Escenarios Prospectivos-Programa de las Naciones Unidas para el Desarrollo (PAPEP-PNUD), Los conflictos sociales en América Latina, La Paz, 2011.

a Los principales actores del conflicto son: Vecinal/comunal (19\%) y Otros varios (15\%), entre los que se encuentran: actores circunstanciales, grupos irregulares, grupos vinculados a actividades productivas sectoriales y gremiales tales como: hidrocarburos, financieras, mineras, coordinadoras, sindicatos, asociaciones, uniones y educacionales (14\%).

\section{III}

\section{Fragmentación}

Los actores demandantes a nivel regional ponen de relieve una tendencia opuesta: el predominio de una fragmentación de los protagonistas de los conflictos. Los actores más importantes son las organizaciones vecinales (19\%), y es también significativo que el $5 \%$ de los conflictos sea protagonizado por actores circunstanciales 6 , esto es, por

${ }^{6}$ Son actores colectivos que aparecen en el momento del conflicto y luego desaparecen. agrupaciones de individuos que luchan por demandas y necesidades coyunturales y cuya organización se disuelve en cuanto se resuelven esos temas concretos. En este sector es donde más se refleja la tendencia a la espontaneidad de la acción colectiva, encarnando en términos de conflictos esa "modernidad líquida" a la que se refiere Bauman (1999 y 2005). Todo esto permite plantear la hipótesis de que se está frente a una situación en que predominan Estados con debilidad institucional y sociedades policéntricas. 


\section{IV}

\section{Centralidad}

A pesar de la centralidad de las demandas al Estado, se experimentan, sin embargo, situaciones muy variadas, desde países con mayor capacidad estatal (Uruguay) y por ende con mayor capacidad de procesamiento de conflictos, hasta países en los que estas capacidades son menores, como Bolivia (Estado Plurinacional de), el Perú y el Ecuador.

Desde una perspectiva general, en prácticamente toda la región, el Estado es percibido como el único actor capaz de dar solución a problemas macroestructurales y a sus manifestaciones a nivel local. Hay una tendencia a la centralización de las demandas sociales que confirma un patrón regional histórico donde el Estado ha jugado y juega un papel protagónico. No hay una distribución equilibrada de los conflictos entre los distintos espacios sociales, y lo más común es que las demandas adquieran una connotación política. Como ya señalaban Calderón y Dos Santos (1987, pág. 15), en América Latina "la carencia de tecnologías constitucionales capaces de institucionalizar el manejo del conflicto" se suma a "las tendencias socialmente excluyentes del orden".

Permanece la paradoja de un Estado débil como principal referente de las intensas demandas sociales: se sigue apelando a un aparato estatal en general pobre e incapaz de dar respuestas institucionales y negociadas, atrapado en las ineficiencias de su burocracia, la inefectividad de su sistema legal, la escasa credibilidad de sus gobiernos y problemas crónicos de corrupción y otorgamiento de prebendas. Al mismo tiempo, el proceso de centralización en el imaginario colectivo llega a los niveles más altos, donde el gobierno central es el Estado y, más aún, el presidente es el Estado, en una trayectoria histórico-cultural en la que el personalismo casi nunca dejó de jugar un papel central en la política latinoamericana.

Finalmente, hay que destacar la importancia del marco normativo e institucional para entender las dinámicas de los conflictos sociales. Ello puede tener gran relevancia para canalizar las tensiones y mantener bajo control potenciales brotes de violencia, organizar las demandas sociales, ofrecer espacios de reconocimiento y expresión a los actores y promover formas políticas y dialogadas de toma de decisiones. Se considera aquí el valor de la democracia en cuanto sistema que establece reglas del juego político capaces de procesar los conflictos (Lechner, 1986). En este sentido, en lo que se refiere al cambio social, parece ser insoslayable la dimensión institucional, como tampoco es posible alcanzar la satisfacción perdurable tanto de las demandas de ciudadanía social como de la participación en la toma de decisiones si no se han superado las limitaciones institucionales (Calderón y Dos Santos, 1987, pág. 17). Asimismo, disfunciones profundas y evidentes de los sistemas institucionales están en la raíz de ejes de conflictividad específicos y, al mismo tiempo, dificultan el manejo de tensiones sociales de distinta naturaleza (tanto por la reproducción social como de tipo cultural y político-ideológico).

\section{Tesis 5}

Existe una tendencia a la descentralización de los conflictos y a la emergencia de experiencias locales de procesamiento democrático de estos. Esta tendencia conduce al desarrollo de una nueva política centrada en relaciones constructivas entre los actores y las gestiones municipales que se caracterizan por ser legítimas y eficaces, poseen agencia ciudadana en los procesos y resultados, y en definitiva construyen una democracia de ciudadanía a escala local.

A pesar de la lógica centralista o de descentralización sin desconcentración de recursos, existen tendencias actuales e históricas a la descentralización de los conflictos en favor del Estado territorial, municipal o regional. Como se ilustra en el gráfico 6 , del total de conflictos registrados en el período de estudio, el 16\% corresponden a demandas dirigidas hacia el Estado local y un $6 \%$ a los gobiernos regionales.

Esta tendencia se relaciona en casos relevantes con la emergencia de actores socioculturales y políticos, que buscarían la expansión de una política constructivista. Como se aprecia en el cuadro 2, los casos de las ciudades de Porto Alegre, Rosario, Bogotá, La Paz y Villa El Salvador, entre otras, son notables ejemplos de aplicación de políticas públicas para procesar conflictos sociales en favor de una democracia plural y sustantiva, capaz de enfrentar mejor los problemas de la desigualdad y el desarrollo.

Estas experiencias y otras similares muestran que es posible encontrar y quizás propagar experiencias en que se procura convertir los conflictos, o parte de ellos, en acuerdos que se transformen en metas y resultados concretos. 
CUADRO 2

Casos paradigmáticos de procesos de descentralización en América Latina

\begin{tabular}{lll}
\hline País & Ciudad & Proceso \\
\hline Brasil & Porto Alegre & Descentralización y democratización local \\
Bolivia (Est. Plur. de) & La Paz & Descentralización y participación popular \\
Argentina & Rosario & Descentralización y democratización local \\
Uruguay & Montevideo & Descentralización participativa \\
Perú & Villa El Salvador & Planeamiento del Desarrollo Participativo y Sistema de Presupuesto \\
Colombia & Bogotá & Descentralización administrativa \\
\hline
\end{tabular}

Fuente: Proyecto Análisis Político y Escenarios Prospectivos-Programa de las Naciones Unidas para el Desarrollo (PAPEP-PNUD), Los conflictos sociales en América Latina, La Paz, 2011.

\section{Tesis 6}

En una lógica desigual y combinada, se desarrollan tres campos de conflicto vinculados a la reproducción social, la lógica institucional y la dinámica cultural. La reproducción social se organiza en una lógica práctica y es un fin en sí misma, pues constituye una referencia ética para la política y la cultura: la dignidad humana.

Con el objetivo de tener una visión regional de las orientaciones de la acción colectiva, en el estudio se identifican tres grandes campos de conflictividad en América Latina, en los que se encuentran subsumidas las diferentes demandas que son la base de las movilizaciones colectivas: i) demandas por la reproducción social, ii) demandas institucionales, y iii) demandas culturales. Los tres campos tienen una racionalidad parcialmente distinta: 1) los conflictos de reproducción social incluyen principalmente las demandas para satisfacer necesidades básicas de bienestar social referidas a un mínimo de vida digna, que permitan la reproducción de los individuos y las colectividades humanas; su lógica es esencialmente práctica; 2) los conflictos institucionales procuran mayor eficacia y legitimidad de las instituciones del Estado; 3) los conflictos culturales tienen como objetivo el cambio de los modos de vida (y en este sentido - como se verá- son conflictos estratégicos).

En el gráfico 7 se muestra el porcentaje de cada campo de conflicto por país y por subregión, pudiendo apreciarse que en la gran mayoría de los países los conflictos por la reproducción social son los más numerosos, con la excepción de Bolivia (Estado Plurinacional de), Colombia, Guatemala, Panamá y la Republica Dominicana, donde pesan más los conflictos institucionales. A su vez, Colombia y México son los países con mayor número de conflictos culturales.

La reproducción social se refiere a las capacidades de una sociedad para reproducirse y cambiar a lo largo del tiempo y se relaciona tanto con umbrales básicos de reproducción (alimentación, salud, educación, empleo, entre otros) como con umbrales ampliados referidos a la calidad de vida en general, y a los conceptos de bienestar y de vida digna en cuanto condición para la libertad real (Sen, 1999). Es en este campo de conflictividad donde se hace más evidente la lógica práctica de la movilización social. La gente sale a la calle para pedir mejoras de sus condiciones de vida y para exigir ciertas garantías en el proceso de reproducción, ya sea en términos de mejores condiciones salariales y de empleo, como de asistencia en temas de salud y educación, o en contra de medidas económicas que se perciben como desestabilizadoras de la situación presente.

La mayoría de los conflictos por reproducción social surgen por cuestiones socioeconómicas, en particular laborales y salariales, de consumo colectivo, pero también en rechazo de ciertas medidas políticas o sociales que se perciben como amenazadoras del statu quo laboral, y asimismo para impulsar normas que podrían mejorar la situación actual, o por cuestiones relacionadas con la propiedad y el aprovechamiento de la tierra (véase el gráfico 8). Más de la mitad de los conflictos por reproducción social radican en demandas de tipo laboral/salarial (59,20\%). La importancia relativa de los conflictos laborales, en particular, demuestra el papel estratégico que cumple el trabajo en la vida de nuestras sociedades, tanto en términos de inserción en las relaciones laborales como de la calidad de la vida social.

Además, los datos sobre los conflictos por reproducción social refuerzan los datos estructurales, en el sentido de que la acción colectiva parece ser consistente con los problemas socioeconómicos reales percibidos a nivel regional. Los conflictos por la reproducción social representan el 47,3\% del total de conflictos a nivel latinoamericano, y su importancia relativa aumenta si se considera que en 12 de los 17 países de la región estos 
GRÁFICO 7

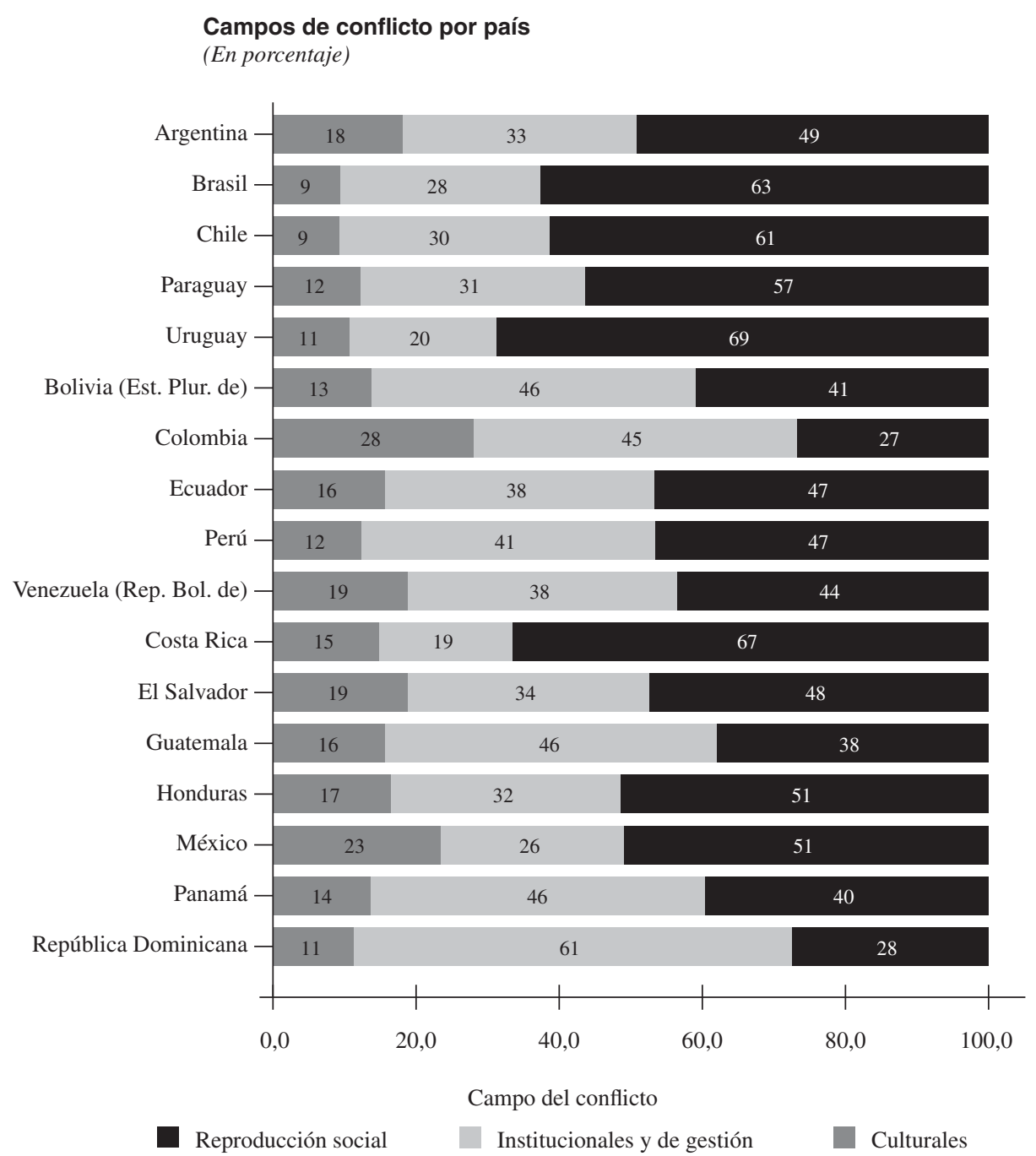

Fuente: Proyecto Análisis Político y Escenarios Prospectivos-Programa de las Naciones Unidas para el Desarrollo (PAPEP-PNUD), Los conflictos sociales en América Latina, La Paz, 2011.

GRÁFICO 8

Tipología de los conflictos

(En porcentaje)

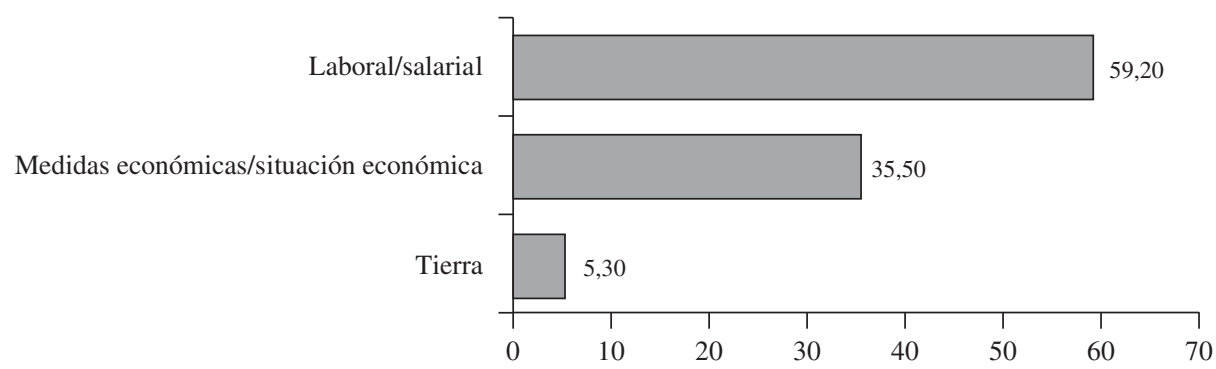

Fuente: Proyecto Análisis Político y Escenarios Prospectivos-Programa de las Naciones Unidas para el Desarrollo (PAPEP-PNUD), Los conflictos sociales en América Latina, La Paz, 2011. 
conflictos son los más numerosos, mientras que en 9 de ellos las cuestiones laborales/salariales y la situación económica se hallan en la raíz de más del 50\% de los conflictos.

A nivel de subregiones, los países andinos y Centroamérica tienen niveles parecidos de conflictividad por reproducción social (que representa cerca del $42 \%$ del total de los conflictos en estas regiones), mientras que en el Cono Sur se observa una cantidad de conflictos relativamente más alta $(58,7 \%)$ (véase el gráfico 9$)$.

En este campo de conflictividad, los conflictos que tienden a alcanzar un nivel de radicalización significativa obedecen a problemas de tierra (53\%), cuestiones laborales/salariales $(49 \%)$ y protestas en contra de medidas económicas (42\%) (véase el gráfico 10).

Los datos concernientes a promedios confirman que los conflictos más radicalizados son los de tierra. Si bien se trata de conflictos menos relevantes en términos de cantidad, presentan una mayor tendencia a la violencia con respecto a otros casos. Esto hace suponer que, por una parte, existe una carencia de espacios institucionales donde encarar estas demandas y, por otra, estos conflictos tienden a combinarse con otros factores, como el tema de las identidades en el caso de los grupos étnicos, o los intereses económicos y políticos a nivel local, lo que aumenta su carga ideológica centrífuga. Además, la

\section{GRÁFICO 9 \\ Los conflictos por la reproducción social (En porcentaje)}

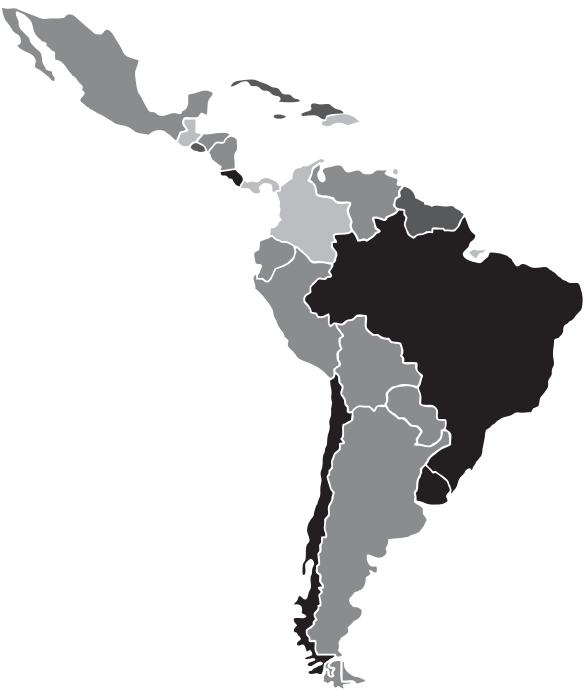

Cantidad de conflictos por país

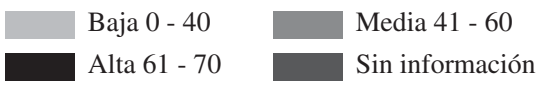

Fuente: Proyecto Análisis Político y Escenarios Prospectivos-Programa de las Naciones Unidas para el Desarrollo (PAPEP-PNUD), Los conflictos sociales en América Latina, La Paz, 2011.

\section{GRÁFICO 10}

\section{Niveles de radicalización}

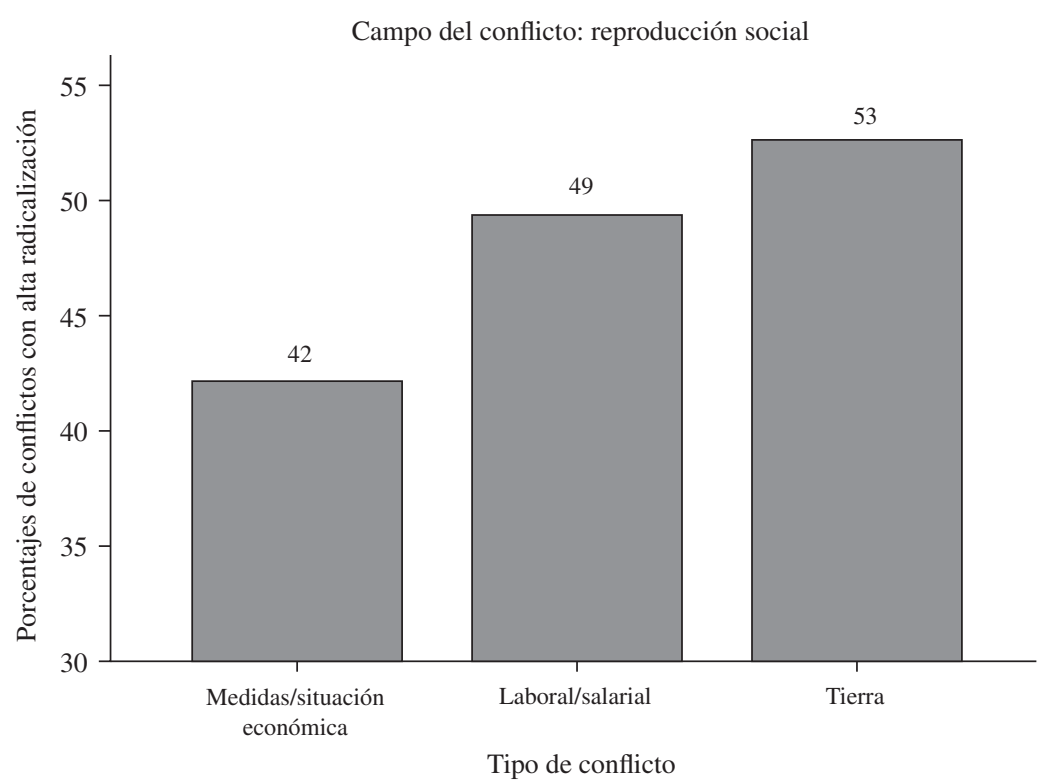

Fuente: Proyecto Análisis Político y Escenarios Prospectivos-Programa de las Naciones Unidas para el Desarrollo (PAPEP-PNUD), Los conflictos sociales en América Latina, La Paz, 2011. 
cuestión agraria sigue siendo un punto pendiente en la agenda de las reformas de muchos países latinoamericanos y permanecen vigentes las consecuencias sociales de un sistema latifundista "neofeudal", fuertemente arraigado en la región.

\section{Tesis 7}

Los conflictos institucionales reclaman la eficacia y la eficiencia de las instituciones. Un rasgo generalizado en la región es la fuerza de una cultura del conflicto de carácter "parainstitucional".

El conflicto institucional es el resultado de la inconsistencia entre las demandas de la gente y la incapacidad de las políticas y las instituciones del Estado para satisfacer tales demandas.

En particular, emerge una conflictividad cuyo énfasis está puesto en el funcionamiento institucional o estatal y no tanto en el cuestionamiento al sistema que, por cierto, constituye en algunos casos un sustrato discursivo general.

Los conflictos que entran en esta categoría se basan en la necesidad de un mejoramiento de la institucionalidad, entendida en sus aspectos más prácticos como gestión administrativa, prestación de servicios públicos, problemas legales y judiciales y legitimidad de las autoridades públicas. Las luchas surgen tanto debido a la falta de institucionalidad como a la demanda de institucionalización de los actores sociales.
Muchos de los conflictos que caracterizan a América Latina se derivan de las debilidades de aplicación de las normas y de las ineficiencias del Estado, más que de una ausencia de normas e instituciones. El Estado, en este sentido, es un importante productor de conflictividad.

La conflictividad institucional es el segundo campo cuantitativamente más relevante (representa el 37,7\% del total de conflictos) e incluye demandas generadas principalmente por fallas en la gestión administrativa (35\%) y por prestación de servicios públicos $(30,2 \%)$ (véase el gráfico 11). Las primeras comprenden demandas generadas por observaciones o desacuerdos respecto de la manera en que se realiza la gestión institucional, tanto en el ámbito público como en el privado; mientras que las segundas se refieren a todo conflicto provocado por falta o deficiencia en las obras públicas (caminos, escuelas, hospitales y otros) en una determinada zona, así como por las limitaciones del Estado para cumplir con el otorgamiento de servicios básicos.

En cuanto a la distribución de los conflictos institucionales en las subregiones, el área donde se concentra la mayor cantidad de estos conflictos es la de los países andinos (41,2\% del total), especialmente en Bolivia (Estado Plurinacional de) y Colombia. Del total de los conflictos en Centroamérica, México y la República Dominicana, los temas institucionales ocupan el $41 \%$ del total. En esta subregión destacan dos grupos de países: por una parte, Panamá, Guatemala y

GRÁFICO 11

\section{Tipología}

(En porcentaje)

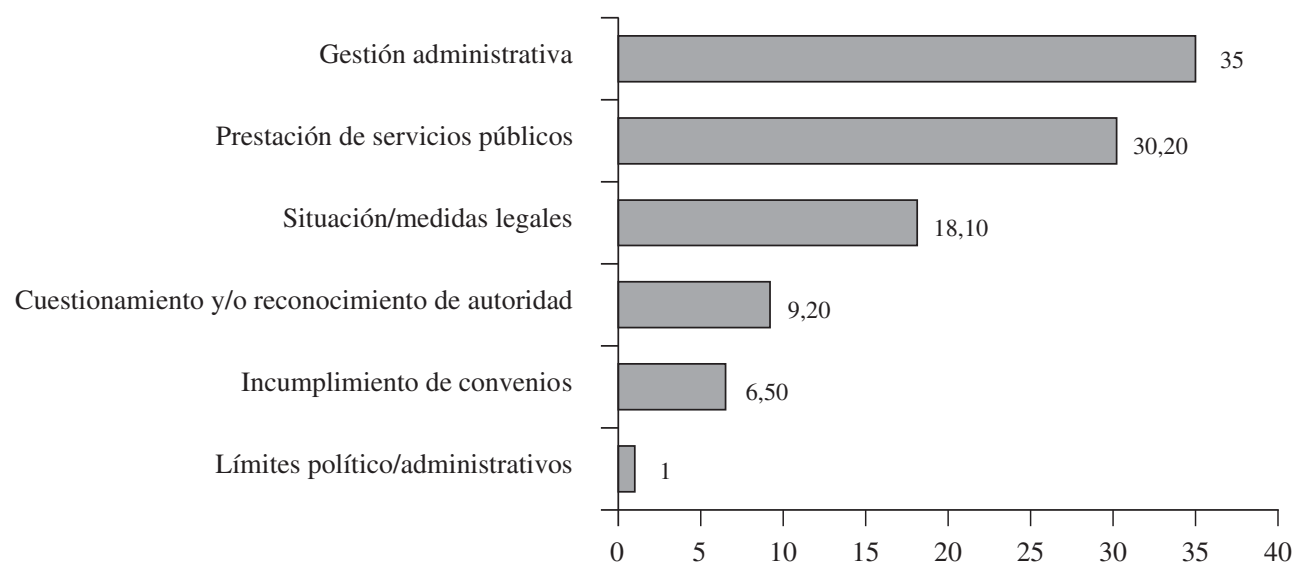

Fuente: Proyecto Análisis Político y Escenarios Prospectivos-Programa de las Naciones Unidas para el Desarrollo (PAPEP-PNUD), Los conflictos sociales en América Latina, La Paz, 2011. 
la República Dominicana, donde los conflictos institucionales constituyen el campo de conflictividad más relevante; por otra, Honduras, el Salvador, México y Costa Rica con niveles medio/bajos de conflictividad institucional. Finalmente, el Cono Sur presenta el $28,7 \%$ de los conflictos institucionales, con niveles por lo general medios (la excepción es el Uruguay, donde solo el $20 \%$ es representado por esta categoría) (véase el gráfico 12).

Los conflictos que más a menudo tienden a alcanzar un nivel de radicalización importante obedecen a problemas de límites político-administrativos (56\%), cuestionamiento o reconocimiento de autoridad (49\%), gestión administrativa (41\%), incumplimiento de convenios (53\%), prestación de servicios públicos (40\%) y situación/medidas legales (28\%) (véase el gráfico 13). Por otra parte, el promedio de radicalización es más alto en el caso de los conflictos debidos a incumplimiento de convenios y relativamente más bajo en las luchas sobre límites administrativos y medidas legales. La cantidad de conflictos institucionales y por temas de gestión administrativa que llegan a niveles altos de radicalización revela la existencia de causas estructurales que están en la base de la debilidad crónica de los mecanismos de gobernabilidad e institucionales.

América Latina se caracteriza por la relevancia en muchos contextos de una dimensión "parainstitucional" del conflicto. Existiría una gramática de relaciones entre Estado y grupos sociales que se mueve entre lo formal y

\section{GRÁFICO 12 \\ Los conflictos institucionales \\ (En porcentaje)}

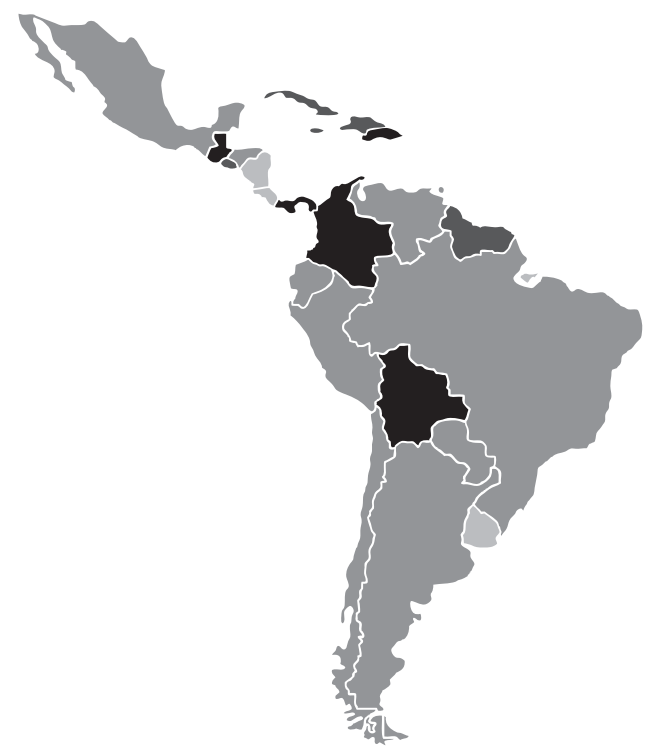

Cantidad de conflictos por país

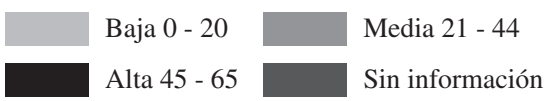

Fuente: Proyecto Análisis Político y Escenarios Prospectivos-Programa de las Naciones Unidas para el Desarrollo (PAPEP-PNUD), Los conflictos sociales en América Latina, La Paz, 2011.

\section{Niveles de radicalización}

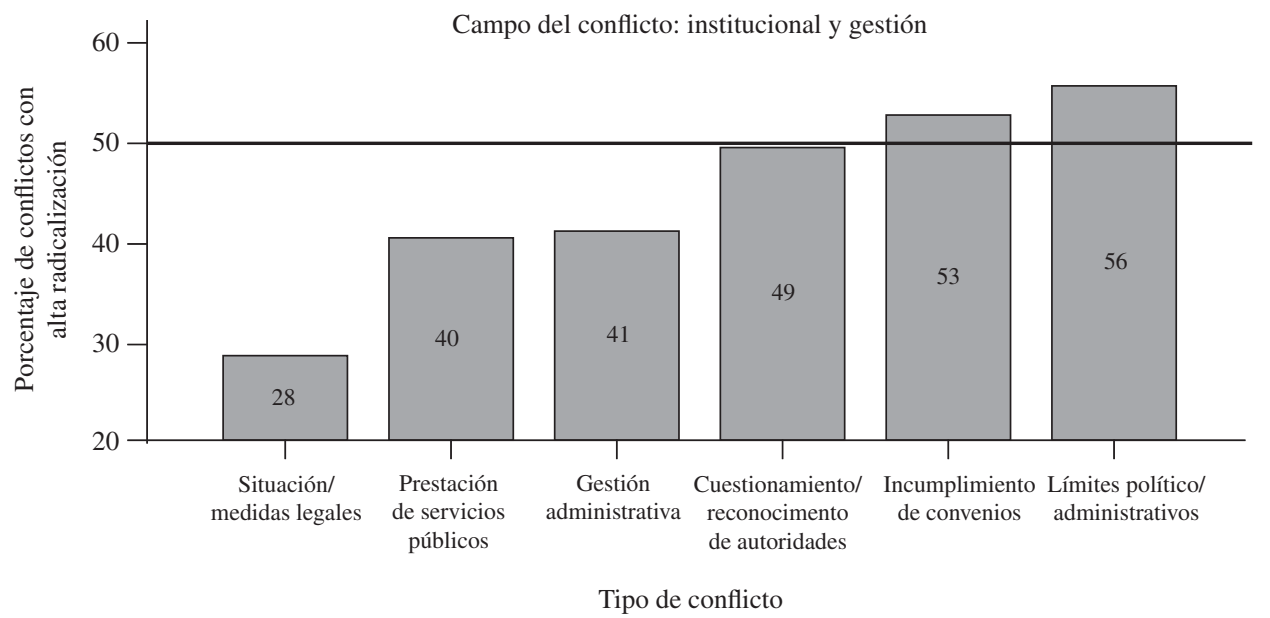

Fuente: Proyecto Análisis Político y Escenarios Prospectivos-Programa de las Naciones Unidas para el Desarrollo (PAPEP-PNUD), Los conflictos sociales en América Latina, La Paz, 2011. 
lo informal. Se trata de sistemas sincréticos que conservan rasgos organizativos y culturales "precapitalistas" y "predemocráticos", combinados con instituciones modernas. En este sentido, las redes personales y las jerarquías informales, encarnadas en los fenómenos del clientelismo y del personalismo, funcionan como mecanismos cotidianos para regular las relaciones sociales entre individuos y con las instituciones formales. En este ámbito "parainstitucional" es donde precisamente se mueven los actores sociales en conflicto ${ }^{7}$.

Por último, independientemente de la orientación política y con algunas variaciones según los casos, en América Latina existe un problema estructural acerca del procesamiento de los conflictos que tiende a degenerar debido a la incapacidad política institucional y estatal de atender las demandas e identificar las necesidades y urgencias de la población. Ello produce una gobernabilidad que tiende a la precariedad.

\section{Tesis 8}

Los conflictos culturales buscan nuevas formas de buena convivencia, tienen efecto sistémico y global, pero son más fragmentados que el resto de los conflictos sociales. Son en gran medida conflictos estratégicos.

La región latinoamericana, como hemos visto, tiene debilidades institucionales crónicas y niveles de desigualdad socioeconómica sobresalientes, siendo en este sentido un terreno fértil para la reproducción de mecanismos de desigualdad cultural también fuertes.

Sobre este tejido de desigualdad compleja se articulan las nuevas necesidades y demandas en la multifacética agenda de movilización cultural de América Latina, en la que sobresalen los conflictos ideológicos y políticos y los de seguridad ciudadana.

A pesar de que los conflictos culturales en todas sus variantes son relativamente menos numerosos con respecto a otros campos de conflictividad, poseen una repercusión sistémica muy alta, gracias al papel que la cultura está teniendo en el nuevo contexto globalizado latinoamericano. Por eso se trataría de conflictos

\footnotetext{
7 Donzelot define el "arte de la negociación" brasileña como esa forma de resolver los conflictos a través de mecanismos informales de arbitraje y negociación, en una práctica en la que se combinan la libre interpretación de los principios legales, la transgresión consentida de las normas y la producción de una legalidad informal con una jurisdicción propia y localizada, libre de las amarras jurídicas y burocráticas del Estado, que dislocan y subvierten la supuesta centralidad y unicidad del derecho formal como regla ordenadora de la vida social (Donzelot, 1994).
}

estratégicos a la hora de entender su impacto en la globalización, la gobernabilidad y la democracia.

En este campo se incluyen aquellos conflictos cuyo fundamento estriba en una definición de cultura en sentido amplio, con un marcado acento en la vida cotidiana, las subjetividades y las identidades múltiples, así como en la industria y el mercado cultural. Estos conflictos son relativamente pocos en comparación con los demás campos (representan el 15\% del total de conflictos); sin embargo, constituyen una categoría cardinal para entender las dinámicas sociales actuales y la gramática de la nueva conflictividad.

En general, las demandas culturales se vinculan al reconocimiento o el fortalecimiento de las identidades de las personas y los actores y a ciertos niveles de calidad de vida, apuntando en abstracto a los derechos de tercera generación y al concepto de ciudadanía cultural. En estos conflictos se expresa la necesidad de afirmar una sociabilización, tanto subjetiva como colectivista, de redefinición de las relaciones sociales y condiciones de seguridad aceptables.

Las demandas por seguridad ciudadana generan poco más de un $28 \%$ de los conflictos culturales. Se refieren por lo general a reclamos relacionados con la falta de protección de la población ante hechos delictuales. El segundo tipo de demandas según su importancia lo constituyen aquellas relacionadas con luchas ideológico-políticas (cerca del 25,7\%, con un total de 89 conflictos). Se trata de pugnas entre facciones - generalmente entre partidos políticos, grupos internos que los conforman o sectores afines- en torno de visiones ideológicas contrapuestas llevadas al plano del enfrentamiento. Cerca del $24 \%$ de los conflictos culturales son suscitados por problemas en el uso de los recursos naturales y el deterioro de la calidad ambiental debido a acciones específicas efectuadas por instancias públicas privadas o ambas (véase el gráfico 14). Estas demandas, dependiendo de los casos, conciernen más a referentes ecologistas o a una perspectiva instrumental de control de los recursos naturales. El éxito de estos movimientos podría deberse en parte a su capacidad de involucrar a lo particular en lo universal, enfatizando el patrón actual de desarrollo y algunos valores globalizados difíciles de cuestionar, como la protección del ecosistema global.

A nivel de subregiones, la de Centroamérica, México y la República Dominicana muestra un 16,3\% de conflictos culturales sobre el total de conflictos; los países andinos, un $15,5 \%$ y el Cono Sur, un $12,6 \%$. En los Andes septentrionales es donde se hallan algunos de los países con más conflictos: Colombia y Venezuela 
GRÁFICO 14

Tipología de los conflictos culturales

(En porcentaje)

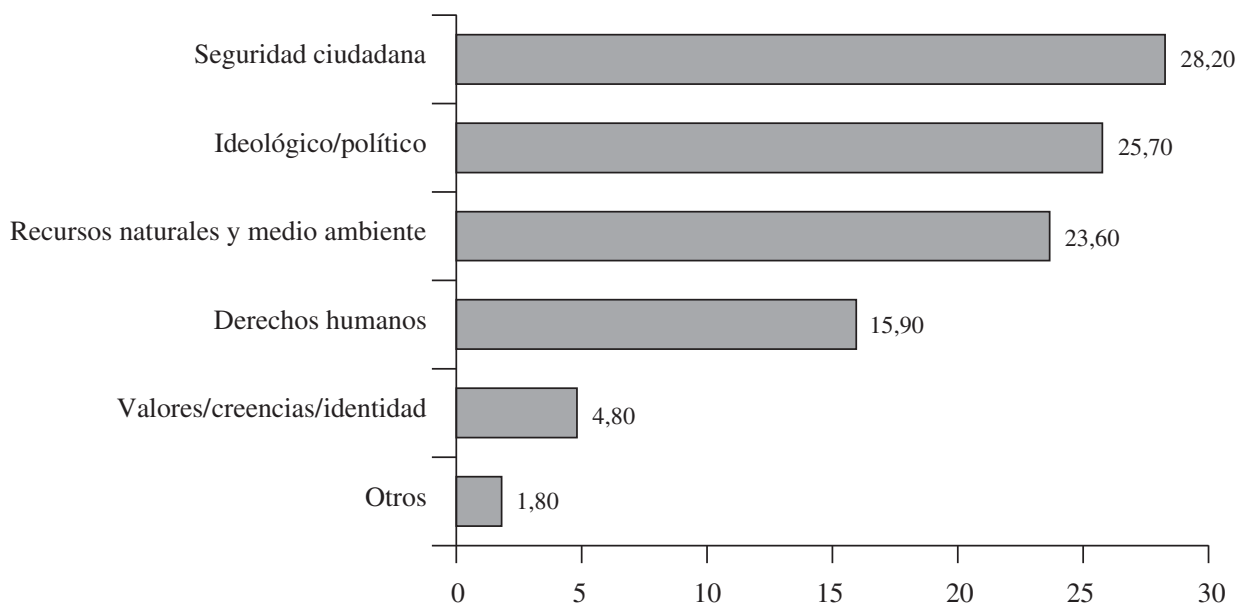

Fuente: Proyecto Análisis Político y Escenarios Prospectivos-Programa de las Naciones Unidas para el Desarrollo (PAPEP-PNUD), Los conflictos sociales en América Latina, La Paz, 2011.

(República Bolivariana de). En el Cono Sur se observa un patrón por lo general medio, con dos tendencias: por una parte, la Argentina, con el mayor número de conflictos culturales en términos absolutos y, por otra, el Brasil y Chile. Finalmente, en Centroamérica y América del Norte destacan El Salvador y México con altos niveles de conflictividad, lo que puede explicarse parcialmente por la diversidad étnica y, sobre todo, los altos niveles de inseguridad y violación de derechos humanos que se están registrando en estos países (véase el gráfico 15).

Los conflictos que más se radicalizan en términos porcentuales son los ideológico-políticos (34\%), seguidos de los que atañen a la seguridad ciudadana (32\%), las luchas por temas medioambientales (26\%), las disputas por los derechos humanos (20\%) y, finalmente, aquellos relativos a valores, creencias e identidades (13\%) (véase el gráfico 16). En cuanto a los promedios de radicalización de los conflictos culturales, las luchas ideológico-políticas o por temas de seguridad ciudadana son las que tienden a ser más violentas. La categoría que alude a otros conflictos registra un $17 \%$.

En general, la radicalización política e ideológica parece ser un factor que afecta seriamente a la gobernabilidad y la convivencia democrática, debido al riesgo de degenerar en niveles de confrontación y enfrentamiento violento. En este sentido, parece fundamental la definición de acuerdos para la convivencia político-ideológica en espacios democráticos compartidos.

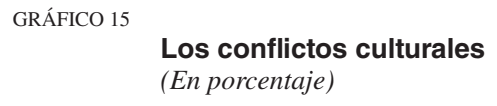

GRÁFICO 15

Los conflictos culturales (En porcentaje)

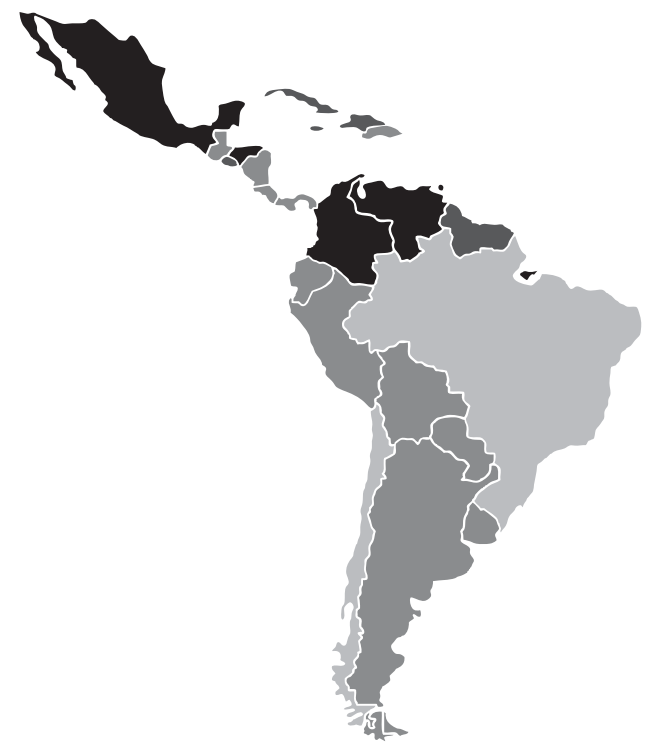

Cantidad de conflictos por país

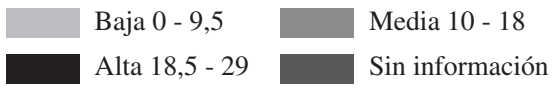

Fuente: Proyecto Análisis Político y Escenarios Prospectivos-Programa de las Naciones Unidas para el Desarrollo (PAPEP-PNUD), Los conflictos sociales en América Latina, La Paz, 2011. 
Por último, en el ámbito de los conflictos culturales, los jóvenes parecen tener un papel fundamental como sujetos de la movilización y productores de nuevas demandas sociales. La tendencia a la movilización ha sido enfatizada también debido a una considerable frustración de expectativas entre los jóvenes, causada por el saldo socioeconómico negativo del período anterior, la desconfianza institucional y la rápida incorporación en la cultura "informacional". Esa frustración es uno de los motores de los conflictos, junto con la percepción de inseguridad y exclusión, como factores inherentes a la vida cotidiana, un proceso de ruptura de los imaginarios y las tensiones entre lo colectivo y lo individual. Los jóvenes son un sector crucial de la sociedad, como portadores de grandes potencialidades de cambio y nuevas propuestas, y al mismo tiempo, una caja de Pandora que puede llegar a generar caos si no se logra canalizar sus demandas, expectativas y frustraciones. En este sentido, los jóvenes son como los conflictos: potencialmente peligrosos y al mismo tiempo renovadores del orden social. Las mujeres también son actrices fundamentales en los conflictos culturales. Si bien las tensiones relativas al género se expresan y reconocen poco en el espacio público mediático, poseen un potencial de cambio cultural y estratégico para las sociedades modernas, especialmente debido al papel propositivo que la mujer puede cumplir en la política y en la sociedad como promotora de cambio y de justicia.

\section{Tesis 9}

Existe una tendencia creciente de los conflictos y de los actores clásicos y nuevos a desplazarse hacia las redes de información y comunicación.

La región se inserta en un nuevo sistema global constituido por redes de intercambio y flujos de comunicación en tiempo real. Estas nuevas formas de comunicación, de conocimiento y de estilo de vida incorporadas por la sociedad dan lugar a lo que Castells denomina la "sociedad red" (Castells, 1997).

La red se ha convertido en el lugar donde se expresan y desarrollan las nuevas formas de conflicto y poder.

GRÁFICO 16

Niveles de radicalización de los conflictos culturales

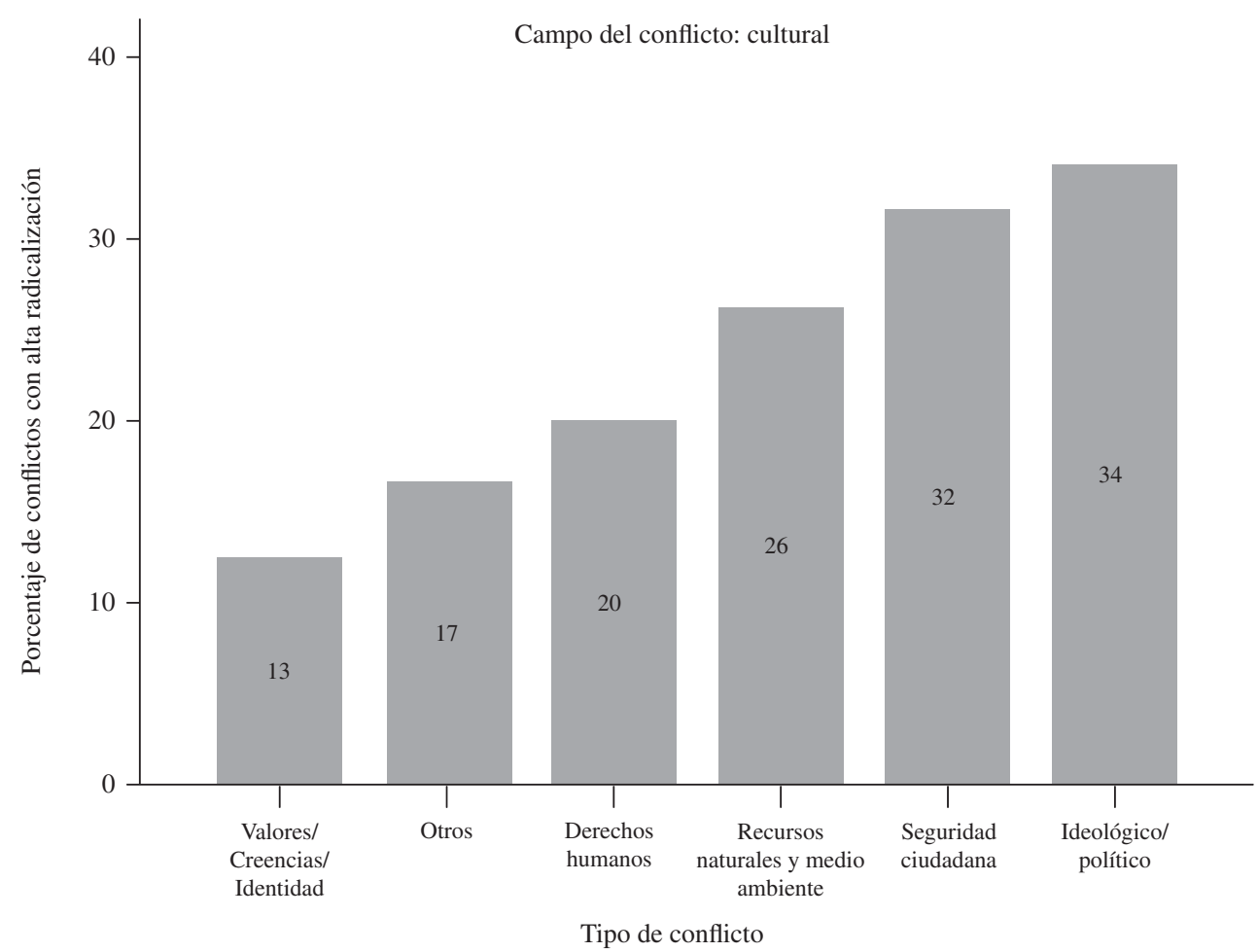

Fuente: Proyecto Análisis Político y Escenarios Prospectivos-Programa de las Naciones Unidas para el Desarrollo (PAPEP-PNUD), Los conflictos sociales en América Latina, La Paz, 2011. 
La cultura de la "tecnosociabilidad" no solo cambia la vida cotidiana de las personas y las comunidades, sino también la política. En cuanto a los conflictos sociales, la política mediática cumple un papel relevante, puesto que realizar una protesta o una marcha en que no estén presentes los medios de comunicación verticales (televisión, radio y periódicos) u horizontales (Internet y teléfonos celulares) se traduce en una baja repercusión de la demanda y menores probabilidades de que esta sea satisfecha.

Las nuevas formas de comunicarse han determinado la utilización intensiva de las tecnologías de la información y las comunicaciones (TIC) en el espacio público. Este se entiende como el lugar de "encuentro", donde las ideas y los valores se forman, se transmiten, se respaldan y combaten (Castells, 2009). Las TIC permiten una manera de interactuar más ágil, flexible y espontánea entre los actores, quienes gracias a ellas pueden ejercer una participación más activa en la política. De esta forma se amplían las posibilidades de acción colectiva debido al fácil acceso y a los bajos costos de uso tanto de Internet como de las telefonías móviles ${ }^{8}$. Participar en un foro, un blog o un grupo dentro de una red social está más al alcance que otras formas de participación política. No obstante, en la sociedad de la información se reproducen las brechas sociales estructurales de la

${ }^{8}$ En el período 2002-2010, gran parte de los países de la región han duplicado el nivel de uso de Internet (Informe Latinobarómetro, 2010 ) y alrededor del $80 \%$ de los latinoamericanos poseen y utilizan un teléfono celular (International Telecommunications Union, ITU). sociedad latinoamericana. Y si los países de la región continúan con la lógica "informacionalista" sin dar un salto hacia el modelo que caracteriza a la sociedad de la información, no se logrará la capacidad económica para integrar a la población en un proceso de desarrollo incluyente (Calderón, 2003).

Como se puede observar en el gráfico 17, existe una relación directa entre el índice de desarrollo humano (IDH) y el porcentaje de uso de Internet. Países como la Argentina y Chile son los que, según los datos, lideran ambos indicadores, mientras que el Paraguay, Honduras y Guatemala se encuentran en el otro extremo.

Estos datos se pueden interpretar como la existencia de un proceso de retroalimentación (feedback loop) entre las dos variables. Es decir, el acceso a las TIC y sobre todo a Internet se podría considerar un factor que favorece directa e indirectamente a los índices de desarrollo, pues se trata de herramientas que pueden mejorar el grado de información y participación social y política de las personas, así como sus condiciones básicas de vida en términos de alimentación, salud y educación; aunque también pueden ser recursos de dominación. En tal sentido, "la tecnología es un instrumento del crecimiento y el desarrollo" (PNUD, 2001, págs. 29-30). América Latina se enfrenta a un importante desafío: reducir la brecha digital y lograr insertarse en el modelo de crecimiento que se desarrolla en torno de las nuevas tecnologías. Para ello, es relevante facilitar el acceso a las nuevas tecnologías a toda la sociedad, en especial a los jóvenes, y reformar estructuralmente el sistema educativo de modo que en él se adopten las Tic (Calderón, 2003).

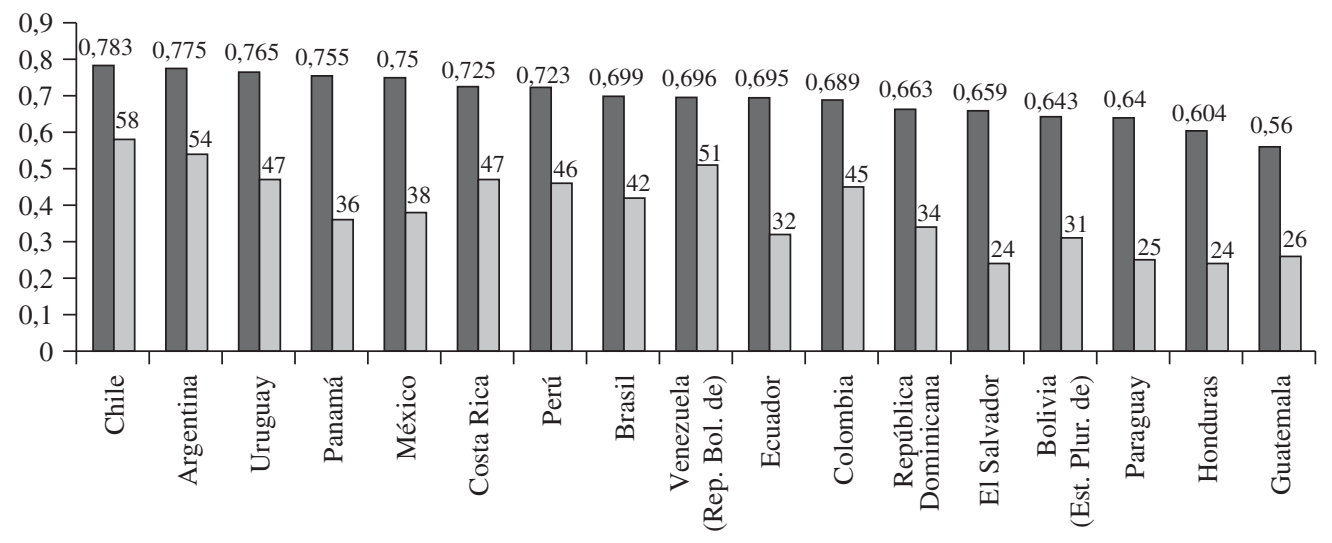

$\square$ IDH $2010 \square$ Uso de Internet por país (porcentaje)

Fuente: Proyecto Análisis Político y Escenarios Prospectivos-Programa de las Naciones Unidas para el Desarrollo (PAPEP-PNUD), Los conflictos sociales en América Latina, La Paz, 2011. 


\section{V}

\section{Los actores en la red}

\section{a) Actores clásicos}

Gran parte de los actores y movimientos socioculturales clásicos latinoamericanos utilizan las páginas web para posicionarse a nivel nacional o internacional. Mediante esta vía difunden sus valores e ideas, aumentando las posibilidades de promover un cambio político o cultural e influenciando la opinión de la gente. Además, el uso de las TIC, en particular de Internet, permite a los movimientos interactuar y coordinar actividades tanto internamente como con otras redes y organizaciones, socializando experiencias.

En el gráfico 18 se muestra que tanto el nivel de desarrollo como el porcentaje de uso de Internet inciden en la cantidad de actores con presencia en la red. Por una parte, países como Costa Rica, la Argentina, el Uruguay y Chile presentan niveles altos de IDH y mayor uso de Internet, y cuentan con un amplio porcentaje de actores representados en la red. En el otro extremo se encuentran el Paraguay, Guatemala y Bolivia (Estado Plurinacional de), los países con menor desarrollo en la región y menor uso de Internet, y en donde existe un porcentaje muy bajo de actores sociales que cuentan con páginas web, blogs o redes sociales para difundir sus demandas.

\section{b) Actores espontáneos ${ }^{9}$}

Estos se caracterizan por emerger a partir de la red, ya que cuando se presenta un malestar o una demanda generalizada esta es transmitida espontáneamente por miles de personas - en un período de tiempo relativamente corto- a través de redes sociales, blogs, foros, cadenas de $e$-mails o mensajes de texto. Mediante estos

\footnotetext{
9 Ejemplos de actores espontáneos en América Latina son: i) los estudiantes "pingüinos" en Chile; ii) el caso de Internet necesario en México, un movimiento generado en Twitter; y iii) un millón de voces contra las FARC iniciado en Colombia. El caso i) se produce en el año 2006 ante las demandas de los estudiantes chilenos por una mejora en la calidad de la educación. El éxito del "movimiento pingüino" fue posible gracias a la organización de los estudiantes que se mantuvieron coordinados mediante el uso de las TIC a lo largo del conflicto. El caso ii) nace en octubre de 2009 en México a través de la red social Twitter, a raíz del malestar de miles de usuarios ante la aprobación en la Cámara de Diputados del aumento en un 3\% del costo de las telecomunicaciones a partir del año 2010. La reacción de los usuarios fue inmediata: "Internet no es un lujo" reclamaban por Twitter, provocando una ciberprotesta entre las 22:00 horas del 19 octubre y las 5:00 horas del 20 de octubre. En el caso iii) se trata de una acción producida en la red social Facebook en enero de 2008 en Colombia, con el objetivo de organizar una marcha masiva a nivel nacional en contra de la violencia. Llegó a contar con 300.000 adherentes (Neumayer y Raffl, 2008) y repercutió no solo en la red social, sino también en los medios de comunicación y en el espacio público real.
}

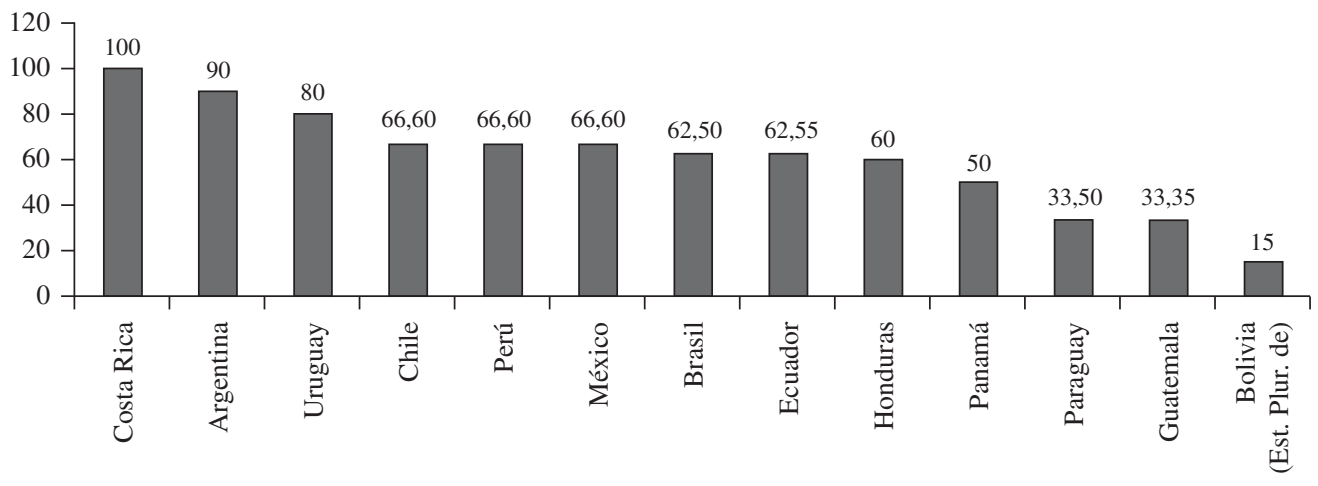

Fuente: Proyecto Análisis Político y Escenarios Prospectivos-Programa de las Naciones Unidas para el Desarrollo (PAPEP-PNUD), Los conflictos sociales en América Latina, La Paz, 2011.

a Solo se consideraron los actores que tuvieron más de cinco episodios conflictivos en un determinado conflicto en el período de estudio. 
instrumentos, los ciudadanos pueden organizarse frente al conflicto y propagar información. De Ugarte (2010) denomina a este fenómeno "ciberactivismo", entendido como una estrategia que busca producir el cambio en la agenda pública difundiendo un mensaje determinado y promoviendo su propagación mediante la transmisión boca en boca, que es multiplicada por los medios de comunicación y publicación electrónica personal. En los últimos años ha habido experiencias en las que el cambio en la agenda pública se ha llegado a concretar exitosamente. Existen dos fases dentro del ciberactivismo: una deliberativa, en que por medio de los blogs y los foros se inicia el debate, y otra de movilización, donde mediante e-mails y mensajes de texto vía celular la gente sale a la calle.

La globalización ha traído como consecuencia el fortalecimiento de las capacidades individuales, en las que prima la espontaneidad, el voluntarismo del activismo político y la autoorganización (Beck y Beck-Gernsheim, 2002); por tanto, se hace indispensable redefinir los proyectos colectivos en la red. "La cuestión es cómo lo individual es resultado de un compromiso colectivo, y cómo lo colectivo puede ser pensado desde la agencia individual" (PNUD, 2009).

\section{Tesis 10}

Una política constructivista produce o mejora una sociedad democrática y constituye un recurso formidable para enfrentar los conflictos y los climas sociales adversos. Los escenarios nacionales son diversos y están vinculados al clima social que se experimenta, así como a la capacidad político-institucional para procesar los conflictos.

La argumentación de esta tesis es esencialmente hipotética y de carácter prospectivo. En ella la pregunta es: ¿Qué condiciones o qué clima social inciden en la dinámica de los conflictos?, y además: ¿Existe la capacidad política e institucional para procesarlos?

El clima social se refiere al conjunto de condiciones objetivas y subjetivas en las que se producen los conflictos, sobre todo aquellas relacionadas con la equidad, la institucionalidad y el multiculturalismo que existen en un país determinado.

La capacidad de procesamiento del conflicto se refiere a la capacidad de trascender hacia un equilibrio caracterizado por un Estado legítimo, con instrumentos y espacios institucionales amplios y eficaces para procesar positivamente los conflictos y, al mismo tiempo, una sociedad activa y caracterizada por una fuerte participación ciudadana en la vida pública y una dinámica de acción colectiva creativa.
En otras palabras, se necesitarían sociedades con actores que no solo protesten, sino que interactúen con otros actores y con el Estado, proyectándose como sujetos autónomos y deliberantes del desarrollo y la democracia.

Los Estados latinoamericanos gestionan, en términos generales, un promedio de 11 conflictos nuevos por mes; los países que registran el número más alto de conflictos son Bolivia (Estado Plurinacional de), el Perú y la Argentina, con un total de conflictos superior a los 200. Por otra parte, los países con menos conflictos de la región son Costa Rica, Chile y El Salvador, con un promedio de 59 conflictos.

Los datos demuestran la existencia de una sociedad latinoamericana con una significativa capacidad de acción social, pero también con importantes asimetrías en las capacidades de movilización: mientras que en un extremo está Bolivia (Estado Plurinacional de) con un promedio de 21,8 conflictos nuevos por mes, en el otro está Costa Rica, con un promedio de 2,3 conflictos por mes (la relación entre ambos promedios es de 9 a 1). Todo esto sin calificar luchas y movimientos sociales específicos.

Ahora bien, no solo se trata de analizar la capacidad que tiene una sociedad de movilizarse o actuar colectivamente, sino que se debe considerar también la capacidad política y social de procesar los conflictos existentes, sean estos pocos o muchos, y el conjunto de imaginarios colectivos sobre el conflicto instalado en una sociedad. Así, un contexto caracterizado por una sociedad y un ambiente político capaces de asumir el conflicto como una oportunidad para la modificación de ciertas condiciones, más que como un perjuicio o un freno para el desarrollo, dispone de mayores capacidades para procesar el conflicto y avanzar democráticamente. En este mismo sentido, una sociedad que se moviliza, pero asume su movilización y el conflicto como una oportunidad para buscar y generar acuerdos (o condiciones para acuerdos) y no como una forma de imponer una visión o una agenda, es una sociedad con capacidad de procesamiento del conflicto.

Entonces, en lo que respecta a la sociedad, la capacidad de procesamiento del conflicto sería, por una parte, la capacidad que esta tiene de actuar en colectivo, de movilizarse y protestar; y por otra, la capacidad de dotar de legitimidad a estos procesos a partir tanto de la socialización de la información, como de la participación de los propios actores bajo una lógica constructivista. Desde el Estado, la capacidad de procesamiento de los conflictos estaría dada tanto por las capacidades institucionales y partidarias para gestionarlos, como por la forma en que el Estado tiende a abordarlos. De tal forma 
que existen Estados con capacidades de gestión de los conflictos mediante una institucionalidad sólida, como también Estados que gestionan los conflictos a través de medios no formales.

Sobre la base de estas variables, se determinaron cuatro escenarios dinámicos (véase el gráfico 19):

- El de países en los que prima la distensión social $\mathrm{y}$ se tiende a un orden conflictivo, constructivo y plural (escenario 1).

- El de países que guardan un orden institucional rígido o desproporcionado, y cuyo abordaje del conflicto tiende a ser represivo o se tiende a negar el conflicto (escenario 2).

- El de países con alta vulnerabilidad a rupturas e importantes limitaciones en la predisposición constructiva hacia el conflicto (escenario 3 ).

- El de países que mantienen un orden inestable debido a sus bajas capacidades de procesamiento del conflicto, y que enfrentan dificultades para gestionar un malestar social generalizado (escenario 4).

A partir de estos escenarios se construyó una tipología dinámica de la situación y las perspectivas de los distintos países, donde se muestra tanto a países con una considerable capacidad de procesamiento de conflictos y un clima de bienestar social (como Costa Rica y el Uruguay), como a otros con serios problemas de clima social y notorias dificultades para procesar conflictos (como Honduras o Guatemala). En todos
GRÁFICO 19

\section{Escenarios del conflicto}

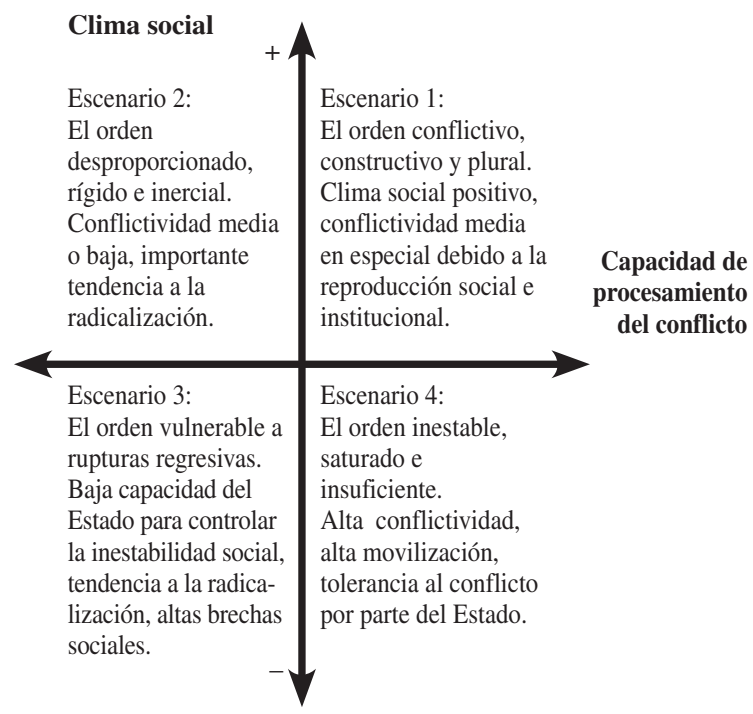

Fuente: Proyecto Análisis Político y Escenarios Prospectivos-Programa de las Naciones Unidas para el Desarrollo (PAPEP-PNUD), Los conflictos sociales en América Latina, La Paz, 2011.

los casos se detectaron escenarios de mejoramiento de las dos variables en juego. En el gráfico 20 se ilustran las situaciones y las probables trayectorias históricas en la región.

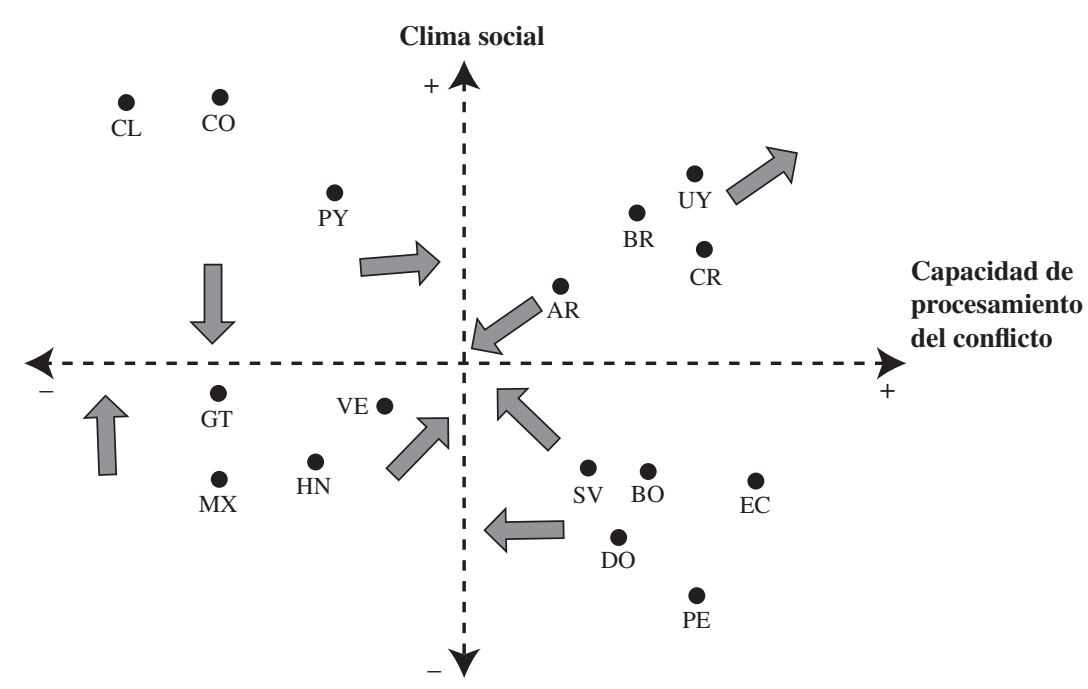

Fuente: Proyecto Análisis Político y Escenarios Prospectivos-Programa de las Naciones Unidas para el Desarrollo (PAPEP-PNUD), Los conflictos sociales en América Latina, La Paz, 2011. 
Para finalizar, y en síntesis, los países de América Latina comparten rasgos comunes en términos de conflictividad: plataformas de exclusión y desigualdades crónicas mayoritariamente cuestionadas por la ciudadanía, conflictos complejos que relacionan tales desigualdades con el número de conflictos y su intensidad, combinación de protestas sociales que se expresan tanto en el plano social y nacional como en el plano cultural/global, racionalidades prácticas en los conflictos por la reproducción social, que conviven con demandas de mayor eficacia y eficiencia institucional y con conflictos culturales de carácter sistémico. Asimismo, Estados omnipresentes en todas las esferas de los conflictos, con serias limitaciones para procesarlos, y sociedades con conflictos cada vez más fragmentados, nuevos espacios públicos vinculados con sistemas de comunicación donde se representan de manera contradictoria los conflictos, y conflictos que tienden a desplazarse crecientemente hacia las redes de información y comunicación con efectos multiplicadores en los nuevos escenarios de poder. En suma, existe una mayor complejidad social vinculada a sistemas políticos y Estados con relativas y limitadas capacidades de gestionarla. Las situaciones y los escenarios prospectivos son diversos y sus opciones abiertas.

\section{Bibliografía}

Ansaldi, W. (comp.) (1986), La ética de la democracia. Los derechos humanos como límite frente a la arbitrariedad, Buenos Aires, Consejo Latinoamericano de Ciencias Sociales (CLACSO).

Aranibar, A., F. Vázquez y J.C. Garzón (2011), Los caminos diferenciados de la democracia en América Latina. Lecciones aprendidas de la gestión política de la crisis económica internacional, $\mathrm{La}$ Paz, Organización de los Estados Americanos/Programa de las Naciones Unidas para el Desarrollo.

Bauman, Z. (2005), Identidad, Madrid, Losada.

(1999), Modernidad líquida, Buenos Aires, Fondo de Cultura Económica.

Beck, U. y E. Beck-Gernsheim (2002), La individualización: El individualismo institucionalizado y sus consecuencias sociales y políticas, Barcelona, Paidós.

Boudon, Raymond y François Bourricaud (1982), Dictionnaire critique de la sociologie, París, PUF.

Calderón, F. (2008), "Una inflexión histórica. Cambio político y situación socioinstitucional en América Latina”, Revista de la CEPAL, No 96 (LC/G.2396-P), Santiago de Chile.

(2003) ¿Es sostenible la globalización en América Latina? Debates con Manuel Castells, Santiago de Chile, Fondo de Cultura Económica.

(1986), Los movimientos sociales ante la crisis, Buenos Aires, Universidad de las Naciones Unidas (UNU)/Consejo Latinoamericano de Ciencias Sociales (CLACSO)/Instituto de Investigaciones Sociales de la Universidad Nacional Autónoma de México (IISUnam).

Calderón, F. y M. Dos Santos (comps.) (1987), Los conflictos por la constitución de un nuevo orden, Santiago de Chile, Instituto Latinoamericano de Estudios Transnacionales (ILET).

Castells, M. (2009), Poder y comunicación, Madrid, Alianza. (1997), "Economía, sociedad y cultura", La era de la información, tomo 1, Madrid, Alianza.

CEPAL (Comisión Económica para América Latina y el Caribe) (2010a), La hora de la igualdad: Brechas por cerrar, caminos por abrir (LC/G.2432(SES.33/3)), Santiago de Chile.

(2010b), América Latina frente al espejo: Dimensiones objetivas y subjetivas de la inequidad social y el bienestar de la región (LC/G.2419), Santiago de Chile.

(2010c), Panorama social de América Latina 2010, Santiago de Chile.

(2009), CEPALSTAT. Estadísticas de América Latina y el Caribe [en línea] http://websie.eclac.cl/sisgen/ConsultaIntegrada.asp
Corporación Latinobarómetro (2010), Informe Latinobarómetro 2010, Santiago de Chile [en línea] http://www.latinobarometro. org/latino/LATDatos.jsp

De Ugarte, D. (2010), "El ciberactivismo, la nueva revolución de la militancia política. Internet y los celulares son sus armas", La nación [en línea] http://www.lanación.com.ar/nota. asp?nota_id=1049795

Donzelot, J. (1994), L'invention du social: essai sur le declin des passions politiques, París, Seuil.

Forbes (2011), "The world's most powerful people", Nueva York.

Lechner, N. (1986), La conflictiva y nunca acabada construcción del orden deseado, Madrid, Centro de Investigaciones Sociológicas.

Neumayer, Ch. y C. Raffl (2008), "Facebook for protest? The value of social software for political activism in the anti Farc rallies", Salzburg, Universidad de Salzburgo [en línea] http://www.digiactive.org/wp-content/uploads/ research1_neumayerra.pdf

PAPEP-PNUD/Fundación UNIR Bolivia (Proyecto Análisis Político y Escenarios Prospectivos-Programa de las Naciones Unidas para el Desarrollo) (2011), Los conflictos sociales en América Latina, La Paz.

PNUD (Programa de las Naciones Unidas para el Desarrollo) (2010), Informe regional sobre desarrollo humano para América Latina y el Caribe 2010. Actuar sobre el futuro: Romper la transmisión intergeneracional de la desigualdad, Nueva York.

(2009), Informe sobre desarrollo humano para Mercosur 2009-2010, Buenos Aires, Libros del Zorzal.

(2004), La democracia en América Latina. Hacia una democracia de ciudadanos y ciudadanas, Buenos Aires, Alfaguara. (2001), Informe sobre desarrollo humano: Poner el adelanto tecnológico al servicio del desarrollo humano, Nueva York.

Sen, A.K. (1999), Development as Freedom, Nueva York, Knopf.

Touraine, A. (1988), La parole et le sang, París, Odile Jacob.

UIT (Unión Internacional de Telecomunicaciones) (2009), "World Telecommunication Indicators Database”, Ginebra [en línea] http://www.itu.int/ITUD/icteye/Reporting/ShowReportFrame. aspx?ReportName=/WTI/CellularSubscribersPublic\&ReportFor mat=HTML4.0\&RP_intYear=2009RP_intLanguageID=1\&RP_ bitLiveData=False

Vattimo, G. (2006), "Conferencia en La Moneda”, Santiago de Chile. Vega, J.E. (2004), "Diversidad, igualdad y exclusión, multiculturalismo y democracia: promesas y problemas", Multiculturalismo y democracia, F. Calderón, La Paz, Programa de las Naciones Unidas para el Desarrollo (PNUD). 